\title{
Impact of land-surface initialization on sub-seasonal to seasonal forecasts over Europe
}

Chloé Prodhomme ${ }^{1}$, Francisco Doblas-Reyes ${ }^{1,2,3}$, Omar Bellprat $^{1,3}$, Emanuel Dutra ${ }^{4}$

${ }^{1}$ Catalan Institute of Climate Sciences (IC3), Barcelona, Spain

${ }^{2}$ Catalan Institute for Research and Advanced Studies (ICREA), Barcelona, Spain

${ }^{3}$ Barcelona Supercomputing Center-Centro Nacional de Supercomputación (BSC-CNS), Barcelona, Spain

${ }^{4}$ European Centre for Medium-Range Weather Forecasts (ECMWF), Reading, UK

Submitted to Climate Dynamics

Corresponding author: Chloé Prodhomme, chloe.prodhomme@ic3.cat

25th October 2015 



\section{Abstract}

2 Land surfaces and soil conditions are key sources of climate predictability at the 3 seasonal time scale. In order to estimate how the initialization of the land surface affects

4 the predictability at seasonal time scale, we run two sets of seasonal hindcasts with the 5 general circulation model EC-Earth2.3. The initialization of those hindcasts is done 6 either with climatological or realistic land initialization in May using the ERA-Land re7 analysis. Results show significant improvements in the initialized run occurring up to the 8 last forecast month. The prediction of near-surface summer temperatures and 9 precipitation at the global scale and over Europe are improved, as well as the warm 10 extremes prediction. As an illustration, we show that the 2010 Russian heat wave is 11 only predicted when soil moisture is initialized. No significant improvement is found for 12 the retrospective prediction of the 2003 European heat wave, suggesting this event to 13 be mainly large-scale driven. Thus, we confirm that late-spring soil moisture conditions 14 can be decisive in triggering high-impact events in the following summer in Europe. 15 Accordingly, accurate land-surface initial conditions are essential for seasonal 16 predictions. 


\section{Introduction}

18 In the context of global warming and the associated increasing number of extreme events, such as heat waves, droughts and floods, the predictability at seasonal time scale of extreme temperature and precipitation events appears to be crucial for climate services, adaptation and risk management (Challinor et al. 2005; García-Morales and Dubus 2007; Thomson et al. 2006). The feasibility of seasonal prediction largely rests on the existence of slow, and predictable, variations in the ocean surface temperature, sea ice, soil moisture and snow cover, and how the atmosphere interacts and is affected by these boundary conditions (Shukla and Kinter 2006). Ocean anomalies associated with El Niño - Southern Oscillation (ENSO) and other ocean phenomena, soil moisture, snow, and ice cover should be taken into account when initializing the predictions (Balmaseda et al. 2008; Balmaseda and Anderson 2009). Unfortunately, less information is available about the state of the climate components other than the atmosphere (Balmaseda et al. 2007; Saha et al. 2010). Due to this source of initial-condition uncertainty, but also other limitations as model inadequacy, and lack of appropriate computational resources, the ability to make predictions on time scales longer than two weeks is still limited (Palmer et al. 2005; Palmer et al. 2005b; Lee et al. 2011). However, in the past years due to increase of the resolution (Fosser et al. 2014; MacLachlan et al. 2014), the development of better initialization products (Guemas et al. 2014; Balmaseda et al. 2009; Balsamo et al. 2015; Dee et al. 2009), and the improvement of model physics (Hourdin et al. 2013; Frenkel et al. 2012) the skill of climate predictions at seasonal and longer time scales has improved (Doblas-Reyes et al. 2013).

Despite the global improvement of seasonal prediction, our ability to forecast temperature and precipitation in some regions such as Europe remains relatively low. On one side, the pronounced warming trend since the 1980s is well captured by most of the seasonal retrospective forecasts over Europe, which provides significant skill for two meter temperatures (t2m, hereinafter) in this region (Doblas-Reyes et al. 2006). On the other side, the skill of predicting the variability around the warming trends is much lower (Weisheimer et al. 2011). This is mainly because the climate variability over Europe is controlled by a variety of mechanisms, such as, the North Atlantic Oscillation (NAO, Rogers 1997; Rodwell et al. 1999), the anomalous frequency of a set of weather regimes (Reinhold and Pierrehumbert 1982; Cassou et al. 2005; Wang et al. 2011), complex teleconnections with the Arctic (Cohen et al. 2014) and with the tropics (Kutiel and Benaroch 2001; Shaman and Tziperman 2011; Behera et al. 2012), and the coupling between the atmosphere and the land surface (Fischer et al. 2007; 
51 represented in coupled models, which could explain the poor skill over Europe (Seneviratne et 52 al. 2010; Kim et al. 2012; Scaife et al. 2011). In an early study, Schär et al. (1999) had shown

53 the existence of a soil-precipitation feedback over Europe. Later on, soil has been shown to 54 influence precipitations, temperature and extreme temperature over Europe; (Fischer et al. 55 2007; Douville 2010; Seneviratne et al. 2006, 2010, 2013; Quesada et al. 2012; Bellprat et al. 56 2013).

57 For instance, Seneviratne et al. (2010) described the soil moisture-temperature coupling 58 feedback loop in which, when an anticyclonic anomaly is present over Europe the soil moisture 59 content will either amplify or moderate the surface temperature response. If the soil is moist 60 (energy limited regime) the available surface energy will preferentially dissipate into latent heat 61 fluxes and dampen surface heating. Conversely, when the soil is dry (soil moisture limited 62 regime) more energy is available for sensible heating, inducing an increase of near-surface air 63 temperature (Seneviratne et al. 2010; Hirschi et al. 2011).

64 As soil moisture partly controls the occurrence of warm events over Europe, a correct 65 initialization of soil moisture content might be essential to correctly forecast summer extreme 66 temperatures. This problem was studied by the global land-atmosphere coupling experiment 67 (GLACE) intercomparison project (http://gmao.gsfc.nasa.gov/research/GLACE). The first phase 68 (GLACE-1) focused on predictability that arises from soil moisture anomalies and determined 69 the geographical regions where soil moisture exerts a significant influence on surface air temperature and precipitation (hot spots) of land-atmosphere coupling (Koster et al. 2004). The second phase (GLACE-2) focused on forecast quality, and assessed the impact of accurate soil-moisture initialization on actual skill using a multimodel approach (Koster et al. 2011). The multimodel mean in GLACE-2 indicates a significant soil-moisture contribution to surface

74 temperature forecast skill in summer with forecast times of up to two months over North and 75 South America (Koster et al. 2010, 2011). While Europe was not then found as a main region of 76 improvement when soil moisture is initialized the GLACE project, numerous other studies have 77 found an impact of soil moisture initialization in Europe (Douville 2010; van den Hurk et al. 2010; 78 Materia et al. 2014).

79 In the present study, the predictability associated with soil moisture at seasonal time scales is 80 revisited with a focus on Europe. The originality of the present study resides in three different 81 aspects. First, the experiments described in this manuscript cover a long period of 30 years 82 instead of the 10 used in GLACE-2. Second, the forecast time has been extended up to 4 83 months, which is longer than most of the GLACE-2 experiments (Koster et al. 2004, 2010). 84 Finally, the initialization of the soil moisture has been performed using the new ERA-Land 
reanalysis (Balsamo et al. 2015), which is expected to provide a good and consistent estimate of soil-moisture initial conditions.

87 The paper is structured as follows. In section 2, the EC-Earth2.3 forecast system, the 88 experimental set up and the forecast quality assessment methods, as well as the definition used 89 for "mid-extreme" events, are described. Section 3 illustrates the impact of the soil initialization 90 on temperature and precipitation skill at the global scale and for extremes over Europe. Section 914 describes in detail the role of soil moisture for the two case studies of summer 2003 and 92 summer 2010. Finally, section 5 offers a summary and the future prospects of the work.

\section{Model and data description}

\section{4}

\subsection{The EC-Earth2.3 forecast system}

The seasonal hindcast experiments are conducted using the EC-Earth2.3 forecast system (Hazeleger et al. 2011). EC-Earth2.3 consists of three model components, the Integrated Forecasting System (IFS) cycle 31r1 for the atmosphere, NEMO2 for the ocean and LIM2 for the sea ice. The model resolution chosen for the atmosphere is a spectral triangular truncation at a wavenumber 159 and for the computation of physical processes reduced Gaussian grid N80, which corresponds to a mesh resolution of around $120 \mathrm{~km}$ in the mid-latitudes, with 62 layers in the vertical. EC-Earth uses the H-TESSEL (TESSEL for Tiled ECMWF Scheme for Surface Exchanges over Land) scheme for the land surface (van den Hurk et al. 2000), which includes an improved representation of hydrology over the TESSEL scheme, in agreement with more recent IFS cycles (Balsamo et al. 2009). The model has four active soil layers extending to a depth of 2.89 meters, without considering capillary rise of groundwater or horizontal exchange of soil water. The oceanic component is NEMO (Madec 2008) using the ORCA1 horizontal resolution (which is $1^{\circ}$ although with a highly irregular, tripolar grid) and 42 vertical levels. The LIM2 sea-ice model is coupled to the ocean (Fichefet and Maqueda 1997). All model components are coupled through the Ocean Atmosphere Sea Ice Soil version 3 (OASIS3; Valcke 2006) coupler.

\subsection{Experimental set up}

To assess the impact of a realistic land-surface initialization on sub-seasonal and seasonal forecasts two seasonal hindcast experiments have been performed. A 10-member, four-month long hindcast experiment has been performed over the period 1981-2010 with start dates the first of May of each year. The ocean, sea-ice and atmospheric components are initialized with ORAS4 (Balmaseda et al. 2013), IC3 sea-ice analysis (Guemas et al. 2014) and ERA-Interim 
117 (Dee et al. 2011), respectively. In the INIT experiment the land surface is initialized with the soil 118 moisture and temperature and snow from ERA-Land (Balsamo et al. 2015), which provides 119 consistent land surface conditions to the forecast system since both share the same land120 surface model version. The ensemble is constructed by using atmospheric singular vectors and 121 the five ocean analyses available from ORAS4. The CLIM experiment initializes the land surface 122 using the climatology of ERA-Land for the corresponding start date, this being the only 123 difference between INIT and CLIM. With this set up, the impact of the land-surface initialization 124 can be isolated from all the other factors that influence the forecast quality in climate 125 forecasting.

\section{$126 \quad 2.3$ Forecast quality assessment}

127 The objective of the present study is to assess how the land-surface initialization affects 128 different aspects of the forecast quality of summer precipitation and temperature, with a specific 129 focus over Europe.

130 For $500-\mathrm{hPa}$ geopotential height, $\mathrm{t} 2 \mathrm{~m}$, precipitation and sea level pressure data from the ERA131 Interim reanalysis have been used as reference (Dee et al. 2011). For precipitation, the 0 to 12 132 hour forecasts have been used. For soil moisture the ERA-Land reanalysis product is used 133 (Balsamo et al. 2015).

134 The skill has been estimated using the correlation of the ensemble mean and the mean 135 anomaly spatial correlation coefficient (MACC, hereafter). We use the Student distribution with $136 \mathrm{~N}$ degrees of freedom to estimate the significance level of correlation, $\mathrm{N}$ being the effective 137 number of independent data calculated following the method of von Storch and Zwiers (2001). 138 The significance of the difference between two correlations is estimated using the methodology 139 of Steiger (1980), which takes into account the dependence from sharing the same observations 140 in both correlation coefficients. In addition, the two methods to assess the significance of 141 correlation and the significance of the difference of two correlations takes into account the 142 independent number of data, which is necessary given the serial correlation typical of the time 143 series considered. As there is no standard method to assess the significance of the MACC and 144 difference between two MACC, we estimated their significance with a bootstrap of 100 random 145 drawings, following the methodology of Masson and Mimack (1992). The drawings are done 146 over the members (random selection of the members with repetition) and over the space 147 (bootstrap by square blocks over the considered region). The block size is estimated by 148 estimating the independent number of data on the longitude and latitude dimensions. 
As we need to assess the contribution of the trend to the skill, we have compared the correlation and the MACC calculated on "raw" and detrended data. The detrended values are the residual of the regression on the global mean two meter temperature (GMT, hereafter) of the concerned variables; the observations are regressed on the observed GMT and both experiments are regressed on their simulated GMT (van Oldenborgh et al. 2013).

154 All the verification, as well as part of the plotting, have been done using the version 2.1.1 of the 155 R-based s2dverification package (http://cran.r-

project.org/web/packages/s2dverification/index.html).

Contrary to the common evaluation in seasonal forecasting, where seasonal means of the variables are analyzed, the skill of daily extremes is also evaluated in this paper. To estimate the daily extremes, we follow the same methodology as Pepler et al. (submitted), which was inspired by Hamilton et al. (2012) and the CECILIA EU project definitions (http://www.ceciliaeu.org/index.htm). The extremes have been calculated using $T x$ and $T n$, the daily maximum and minimum temperature, respectively, estimated from the 6 hourly t2m.

The first set of extremes are the monthly 90th and 10th percentile of $\mathrm{Tn}$ and the 90th percentile of Tx, named hereafter $q 10$ and $q 90$ of $T n$, and q90 of Tx, respectively. For the second set of extremes, the climatological 90th and 10th percentile of Tx and Tn are estimated using data from all years between 1981 and 2010. This is done separately for the ERA-Interim data and for the hindcasts. The frequency of days and nights in a month over and under the corresponding climatological percentile are then estimated. To summarize, the present study will focus on six of these variables:

- q10 of Tn for each month and the percentage of nights in a month under the climatological value of the $\mathrm{q} 10$ of $\mathrm{Tn}$, also called number of cold nights.

- q90 of Tn for each month and the associated number of nights in a month over the climatological value of the $q 90$ of $\mathrm{Tn}$, also called number of warm nights.

- q90 of Tx for each month and the associated number of days in a month over the climatological value of the $q 90$ of $\mathrm{Tn}$, also called number of warm days.

The two first variables, q10 of $\mathrm{Tn}$ and the number of cold nights, correspond to cold extremes while the other four variables are related to warm extremes.

\section{$178 \quad 3$. Results}

\subsection{Impact of land-surface initialization during boreal summer}

180 Figure 1 illustrates the skill of the EC-Earth2.3 system for predicting land $2 \mathrm{~m}$ and precipitation using the correlation between the ensemble-mean prediction and the observational reference. 
182 The results of the CLIM experiment are used as a benchmark. As in most state-of-the-art 183 forecast systems, EC-Earth2.3 shows high skill for t2m over land almost everywhere except 184 over some areas where the observational reference might not be trustworthy (Doblas-Reyes et 185 al. 2013). Statistically significant correlations appear mainly in tropical regions. In contrast, the 186 predictions exhibit lower skill for precipitation, except over a few regions such as those 187 neighboring the Pacific basin and sub-Saharan Africa. An important part of the skill in both 188 temperature and precipitation is linked to ENSO (Landman and Beraki 2012; Phelps et al. 2004; 189 Doblas-Reyes et al. 2013) whose teleconnections over land is well reproduced by the model in 190 most of the relevant areas (Fig. S1).

191 The use of a realistic initialization of soil variables (snow, soil moisture and soil temperature) 192 such as the one used in the INIT experiment compared to the one used in CLIM has generally a 193 positive impact on the skill of seasonal mean t2m (Fig. 1c). Nevertheless, only very few of the 194 positive changes are statistically significant at the $95 \%$ confidence level (black dots), which is 195 the likely result of the small differences and the reduced sample size of the experiment, an 196 aspect that is limited by the observational data available to reliably initialize the hindcasts. The impact of land-surface initialization on the precipitation skill is patchy, although with a tendency to show positive differences in correlation. There is no area with a significant decrease of correlation, whereas a few areas show an important increase of skill (Fig. 1d). The patterns of improvement cannot be simply described by a modification of the ENSO teleconnections over land in INIT compared to CLIM (Fig. S1), because they are very similar in both experiments, and an alternative explanation is needed.

It has to be borne in mind that our study considers longer forecast time scales than the GLACE2 experiment. For instance, no improvement in seasonal skill over the Great Plains emerges in Fig. 1 compared to previous studies. However, consistently with previous studies (Koster et al. 2004, 2010, 2011; van den Hurk et al. 2010), there is an important improvement of skill in June (second forecast month) over the United States, which disappears in July and August (Figs. S2, S3, S4).

209 In order to quantify precisely the impact on skill seen on Fig. 1, Fig. 2 shows scatter plots of the 210 difference of correlation between INIT and CLIM against the correlation in CLIM for both 211 precipitation and $\mathrm{t} 2 \mathrm{~m}$ in different regions. Figure 2 shows the improvement due to the soil 212 initialization for temperature prediction: 65.3\% of the land points have a positive impact (Fig. $2132 \mathrm{~d}$ ). Nevertheless, the correlation difference between INIT and CLIM is significant only in very 214 few cases (red dots), with no significant negative difference (dark blue dots). In general, in all 215 regions, more improvements (positive differences, points where the skill is significant in INIT but 
216 not in CLIM and statistically significant negative correlation decrease) than degradations

217 (negative differences, points where the skill is significant in CLIM but not in INIT and statistically 218 significant negative correlation decrease) are found. This comprehensive analysis shows that 219 the land-surface initialization has on average a positive impact on the temperature skill when 220 large regions are considered.

221 Conversely, for precipitation no clear improvements are visible on Fig. 2h: on one side 53.9\% of 222 the grid points have an increased skill in INIT. On the other side, more points are located in the 223 bottom-right quadrant than in the top-right quadrant, which suggests that more degradations 224 than improvements occur in the areas where CLIM has skill.

225 Figure 2 shows that, for both temperature and precipitation, the lower the skill in CLIM is, the 226 stronger the improvements in INIT are. In addition, the degradation in INIT tends to occur when 227 the skill is already positive in CLIM. This suggests that the land-surface initialization brings skill 228 to regions where the forecast system has no skill, but it can also negatively perturb the system 229 in regions of high skill, suggesting that the large-scale signal can be perturbed by soil moisture 230 initialization. This can be partly explained by the biases in the soil initialization products 231 (Balsamo et al. 2015) and by the initial shock and drift of the soil variables in the forecasts 232 (Dirmeyer 2005; Materia et al. 2014). Furthermore, model inadequacies in the representation of 233 the land and/or land atmosphere coupling might explain the decrease of skill in INIT. Error 234 compensations may take place in CLIM, in other words, CLIM may have skill in some region for 235 the wrong reasons. In this case, a better representation of the soil state might in some region 236 lead to a decrease of skill. An illustration of possible error compensations can be seen over 237 North-Western South America, where the relation between ENSO and $\mathrm{t} 2 \mathrm{~m}$ is reversed 238 compared to the observed one (Fig. S1) while still CLIM has a high t2m skill in this region (Fig. 1 239 and 3).

240 Another factor that can explain the difference in skill between CLIM and INIT is their 241 representation of the recent temperature trends. In fact, recent trends can explain a large part of 242 the seasonal forecast temperature skill (Doblas-Reyes et al. 2006). Figure 3 is similar to Fig. 1, 243 but this time the correlation has been computed using the residuals of the regression of the 244 temperature and precipitation fields on the GMT. The comparison of Figs. 1a and 3a illustrate 245 the important contribution of the trend in the skill of temperature. An important part of the t2m 246 skill is related to the trend, especially over Europe where most of the skill in CLIM is related to 247 the trend (Doblas-Reyes et al. 2006, 2013). Conversely, Figs. 1 and 3 suggest that there is 248 almost no impact on the skill of precipitation from the temperature trend. 
249 For both precipitation and $\mathrm{t} 2 \mathrm{~m}$, the impact of the land-surface initialization remains very similar 250 when the effect of the global-mean temperature is removed (Figs. 1b, 3b). This result, and the

251 inspection of the regression coefficients, suggests that the land-surface initialization affects only 252 marginally the representation of the temperature trend, consistently with the results of Jaeger 253 and Seneviratne (2010). The comparison between Figs. 1c and 3c (see also Fig. S5) gives a 254 hint that the skill improvement in INIT compared to CLIM is slightly stronger when the trend is 255 removed.

256 As most seasonal forecast systems, EC-Earth2.3 shows widespread skill in seasonal-mean t2m 257 and relatively low skill for precipitation forecasts. An important part of the skill for forecasting $258 \mathrm{t} 2 \mathrm{~m}$ is linked to the warming trend. The soil moisture initialization leads to a general 259 improvement of $\mathrm{t} 2 \mathrm{~m}$ skill and to a lesser extent of precipitation skill, occurring mainly in regions 260 where the skill is low in the CLIM experiment. This improvement remains robust when the global-mean trend effect is removed. The rest of the paper focuses on Europe, a region where soil moisture has been shown to have a strong impact, an aspect that is also evidenced in our experiments (Figs. 1, 2; Jaeger and Seneviratne 2010; Hirschi et al. 2011; Quesada et al. 2012; Douville 2010).

\subsection{Summer skill over Europe}

The previous section showed that Europe is one of the regions with the largest impact of the land-surface initialization. However, all the results described concentrate on seasonal averages of temperature and precipitation. Instead, various studies have demonstrated that soil moisture plays an important role in the occurrence of extreme warm events (Jaeger and Seneviratne 2010; Hirschi et al 2011; Hamilton et al. 2012). The prediction of extreme events is highly relevant to society (Wang et al. 2009). Hence, any skill improvements on this aspect might have a larger impact than the more traditional result of the increase in seasonal mean skill. This section focuses on the predictability of "seasonal extremes" or "daily extremes" as defined in Hamilton et al. (2012), Eade et al. (2012) and Pepler et al. (submitted). The extreme variables considered, which were selected because they are the most relevant in summer, are classified in two categories (see Section 2.3):

- The warm extremes: q90 of Tx, number of warm days, q90 of Tn and number of warm nights

- The cold extremes: $\mathrm{q} 10$ of $\mathrm{Tn}$ and number of cold nights

Figure 4 shows the correlation of the ensemble-mean predictions of CLIM for the JJA (onemonth lead time) seasonal mean for the different extreme variables. The correlation for the 
282 individual months is provided in the supplementary material (Figs. S6, S7 and S8, for June, July 283 and August, respectively).

284 Consistent with previous studies, the pattern of extreme temperature skill tends to be similar to 285 that of the mean temperature (Figs. 3a and 4a-f; Hamilton et al. 2012; Eade et al. 2012). The 286 skill is also similar for all the variables inside the two groups of extreme variables (Figs. 4 a-d, e287 f). The similarity is found also when undetrended anomalies are considered (Figs. 1a, S9a-f; 288 Pepler et al., submitted). However, as for the mean temperature, the skill is lower for all extreme 289 variables when the correlation is calculated on detrended anomalies. However, some regional 290 differences appear. The skill of the CLIM experiment for the warm extreme variables in the 291 Mediterranean region is slightly higher than for the seasonal-average $t 2 \mathrm{~m}$ skill, while the skill of 292 the cold extreme variables tends to be higher than the mean $\mathrm{t} 2 \mathrm{~m}$ skill in eastern and northern 293 Europe (Figs. 4 a-f, 3a).

294 The correlation changes in INIT with respect to CLIM are very similar for all the extreme warm 295 variables (Fig. 4g-j). Substantial improvements are found over the Mediterranean region, central 296 Europe and Scandinavia for extreme warm variables (Figs. 4g-j), which are areas of low skill in CLIM (Fig. 4a-d). For the extreme cold variables, the soil moisture initialization leads to a weak improvement over the Mediterranean region and Western Europe and a strong degradation in northeastern Europe (Fig. 4k-I) that might be linked to the different behaviour of the snow melting in the two experiments. These patterns obey to a strong intraseasonal evolution of the skill improvement (Figs. S6-S8), with the skill decrease in northeastern Europe occurring mainly in June and the skill increase in western Europe in July, especially for the warm extremes. To better understand the intraseasonal evolution of the impact of the soil initialization on the skill, the MACC calculated over Europe (20W70ㅌ-25N $\left.75^{\circ} \mathrm{N}\right)$ for CLIM and INIT and the difference between the MACC in both experiments are displayed in Fig. 5. In May (first month of the forecast), Fig. 5a shows that the skill for predicting the mean and the cold extremes is high (up to 0.7), while the skill for the warm extremes is substantially lower (around 0.25). For the CLIM experiment, the skill of all the variables decreases along the forecast time and reaches almost zero in July (Fig. 5a). In INIT, as in CLIM, the skill sharply decreases between May and June, but remains almost constant at $\sim 0.1$ for all variables, which is statistically significant at $95 \%$ but not high enough to be considered useful in term of seasonal forecasting (Fig. 5a).

312 Hence, the positive impact of the soil initialization over Europe is more obvious a few weeks 313 after the forecasts have been initialized and is found for all the variables considered. This can 314 be better observed in Fig. 5b, which displays the difference of MACC between the two 315 experiments. There is almost no difference for the variables in May, while in June the cold 
extremes and the mean $\mathrm{t} 2 \mathrm{~m}$ exhibit a negative impact of land-surface initialization and a positive or neutral impact for the warm extremes. The decrease in skill of the cold extremes in June is related to the important decrease of skill in central Europe (Figs. 6, S5), which occurs for all variables but is stronger for the cold extremes. As in previous cases, the degradation of skill due to the land initialization happens for regions and periods where the skill is high in CLIM (Figs. 4e-f, 5, S3). Conversely, in July and August, when the skill is low in CLIM (Fig. 5a), we observe an important improvement in INIT for all variables, especially for the warm extremes (Fig. 5b). In spite of the positive impact of the land initialization over Europe, different regions experience a different impact. Figure 6 shows the correlation difference for the mean $\mathrm{t} 2 \mathrm{~m}$ and the extreme variables averaged in some of the regions defined in Christensen and Christensen (2007). In two regions of low skill in the CLIM experiment (Scandinavia and eastern Europe; Fig. 4), the land-surface initialization has a positive impact for all variables and during the complete forecast length (Fig. $6 \mathrm{~d}, \mathrm{f}, \mathrm{g}$ ). In the Alps and Mediterranean area, despite a degradation of skill during one forecast month, the skill is generally higher in INIT than in CLIM. In the three other regions considered, France, central Europe and the Iberian Peninsula, the results are less clear with improvement for some variables occurring simultaneously to degradation of other variables. No statistically significant differences can be found, except for the number of warm days in eastern Europe and for the number of warm nights in Scandinavia. In summary, the impact of the land-surface initialization is generally positive on predictions of both the mean $\mathrm{t} 2 \mathrm{~m}$ and extreme temperature variables and is slightly stronger for the warm than for the cold extremes. The improvements last the whole forecast length. However, the results vary from one region to another, and might be associated with the correct prediction of a few events. An analysis of the impact on two of the most relevant events recorded recently over Europe might help interpreting these results.

\section{Predictions of the European summers of 2003 and 2010}

341 Dry soils seem to have played a key role in the development of the 2003 and 2010 heat waves 342 over Western Europe and Russia (Weisheimer et al. 2011; Quesada et al 2012; Fischer 2014).

343 The CLIM and INIT experiments allow investigating the soil contribution to these events and to 344 understand their role in determining the seasonal forecast skill.

345 Figures 7 and 8 illustrate the summer 2003 and 2010 events from observational estimates and 346 their representation in both INIT and CLIM. The left column shows the observed anomalies for 347 five variables: $\mathrm{t} 2 \mathrm{~m}$, precipitation, $500-\mathrm{hPa}$ geopotential height ( $\mathrm{z} 500$, hereafter), sea level 348 pressure (SLP, hereafter) and vertically integrated soil moisture. Dots are used to mark the 
areas where the anomalies are higher than the climatological upper quintile for $\mathrm{t} 2 \mathrm{~m}, \mathrm{z} 500$ and SLP and are lower than the climatological lower quintile for precipitation and soil moisture. The CLIM and INIT results are displayed in the central and right columns, respectively. Instead of displaying ensemble-mean anomalies, which usually are seriously damped when compared to the reference, the forecast odds are computed from the ensemble. The odds are the ratio between the probability for the anomalies to be in the upper quintile, the interquintile range or the lower quintile, and the climatological probability of these three categories (respectively $20 \%$, $60 \%$ and $20 \%$ ). Each point is attributed to the category corresponding to the highest odds ratio. If the point is attributed to the interquintile range or if there is no category assigned (the categories with two highest odds ratio have an equal value) the point is drawn in white. If the point is attributed to the lower/upper quintile category, the corresponding odds ratio is plotted with the left/right color scale. The odds ratio is a useful way of representing the signal in a probabilistic way because it gives an estimate of how anomalous the probability of the event is (i.e. the number of times it can occur above its climatological frequency) independently of the baseline. These figures allow visualizing how the hindcasts predict the extreme quintile categories for each point.

For the 2003 heat wave, Fig. 7 confirms the occurrence of the warm and dry event over Western Europe in 2003. A blocked regime is visible in the geopotential height, with negative anomalies over north-eastern Europe and positive anomalies over the North Atlantic and Western Europe (Fig. 7g; Garcia-Herrera et al. 2010). The blocking regime is also clearly visible on SLP, except over Western Europe where, consistently with García-Herrera et al. (2010) and Fischer et al. (2007b), the heat low mechanism takes place. Both INIT and CLIM are able to forecast with high probability this warm and dry anomaly over Western Europe (Fig. 7 b, c, e, f). A successful prediction of the 2003 heat wave has previously been achieved with retrospective forecasts presented in Weisheimer et al. (2011), where the authors highlighted the crucial role of the land surface for the correct prediction of this event. An initial dry anomaly in spring has further been discussed to have been pre-requisite for the development of the 2003 heat wave (Fischer et al. 2007b; Ferranti and Viterbo, 2006). The fact that both experiments are able to forecast the 2003 heat wave is hence surprising and suggests that the exceptional high temperatures in 2003 may be largely a consequence of a strong 379 dynamical forcing. This is supported further by the fact that, in spite of starting from 380 climatological initial conditions, the CLIM experiment develops a high probability of extremely 381 low soil moisture over the Mediterranean and Western Europe. This result is consistent with the studies of Feudale and Shukla (2011a, 2011b), which suggest oceanic conditions to be a major 
driver of the heat wave. However, the soil moisture, precipitation and temperature are forecasted with higher probabilities in INIT than in CLIM (Fig. 7 b, c, e). Moreover, the spatial pattern of the observed anomalies is better reproduced in INIT than in CLIM. For instance, the dipole structure of temperature and precipitation between north-eastern and western Europe, a characteristic of a blocking regime, is, in contrast to CLIM, reproduced more realistically in INIT. These differences between the two experiments suggest that soil moisture plays a role in maintaining the blocking regime over Europe and for the occurrence or maintenance of the baroclinic anomalies of the heat low mechanism over western Europe, consistently with the studies of Fischer et al. (2007b) and Miralles et al. (2014).

In the case of the 2010 heat wave Fig. $8 \mathrm{a}, \mathrm{d}, \mathrm{g}$ and $\mathrm{m}$ show the occurrence of the warm and dry event over Russia in 2010 associated with a dry soil moisture anomaly and an anticyclone over Russia. This warm and dry anomaly associated to high sea level pressure is substantially higher (or lower for soil moisture and precipitation) than the climatological higher quintile for all concerned variables, consistently with Dole et al. (2011). Unlike 2003, for the summer 2010 event no heat low mechanism takes place associated with the anticyclone and warm and dry anomalies over Russia, although the z500 anomaly is shifted with respect to the SLP anomaly. Figure 8 shows that CLIM is not able to predict with probabilities substantially different from the climatological ones the extreme characteristics of the 2010 Russian heat wave for none of the considered variables, except for the soil moisture anomaly. Conversely, in INIT, high probabilities for warm and dry anomalies are found in Eastern Europe (Fig. 8c, f). Figure 8i shows that INIT predicts relatively well the z500 anomalies, indicating that soil moisture initialization might have a feedback on the atmospheric circulation. Nevertheless as for 2003, the SLP pattern of anomalies is not reproduced correctly in INIT nor in CLIM (Fig. 8k, I). The anomalies of temperature, precipitation are misplaced compared to the observational reference (Fig. 8c, f). In order to better understand how the soil initial conditions can affect the predictability of the event, figure 9 shows for both 2003 and 2010, the soil moisture anomalies, with respect to the daily climatology calculated over 1981-2010, for May 1st. Previous studies have suggested that 411 the 2003 spring was possibly drier than usual (Fischer et al. 2007), however more recent 412 analyses have shown that it was actually likely close to climatology. For instance, in a 413 catchment in Northeastern Switzerland with measurements of whole surface water balance 414 (including soil moisture and evapotranspiration), a recent study (Seneviratne et al. 2012) has 415 shown that soil moisture was not particularly low prior to June 2003. This result was confirmed 416 more broadly for a large part of Central Europe in another study (Whan et al. 2015) based on a 
417 newly derived soil moisture dataset (Orth and Seneviratne 2015). However, Fig. 9 shows that 418 according the ERA-Land product, the soil moisture over western Europe in 2003 exhibit a large 419 dry anomaly over the whole western Europe at the beginning of May. During the course of May, 420 soil moisture dries over western Europe and recovers at the end of the month and then 421 decreases during the whole summer. This behaviour is similar to the one described in Whan et 422 al. (2015) based on the soil dataset of Orth and Seneviratne (2012). The two products have the 423 same evolution during summer 2003 but ERA-Land does have larger soil anomalies than the 424 other product in both June and May.

425 In CLIM, logically, the soil initial condition is very close to 0 , while in INIT the simulation starts to 426 a dryer state, however probably due to the interpolation errors (from T511 to T106) and the drift 427 of the first time steps, the first day is less dry than the observed state. The progressive drying of 428 soil during summer is well reproduced by the two simulations (due to the ensemble averaging 429 the evolution is smoother in the simulation than in the reanalysis). Independently of the initial 430 condition of soil, the successful forecast of temperature and precipitation leads to the correct 431 evolution of the soil during the summer. However, it is not clear from the present experiment to 432 know if in July or August, after the strong drying of June (Fig. 9b and Whan et al. 2015), the soil 433 conditions are important, additional experiments with more start dates would be needed.

434 In 2010, INIT starts with a dry anomalies equivalent to the observed one, while again CLIM 435 starts from 0 (Fig. 9d). Conversely to 2003, the model is unable to forecast the evolution of the 436 soil moisture during the forecast, while the ERA-Land shows a drastic drying during summer, 437 INIT and CLIM keep the same anomaly. So while in INIT, the dry conditions will allow the heat 438 wave to develop the neutral condition in INIT will inhibit its development.

439 To summarize, it seems that the 2003 warm event was predictable even without the correct 440 initialization of the land surface, consistently with the studies of Feudale and Shukla (2011a, 441 2011b). The atmospheric and ocean conditions are enough to generate the dry soil moisture 442 anomalies (Fig. 7h and 9b). This last feature shows that the atmospheric circulation was 443 predictable by the model even without the correct soil-moisture initial condition. It hence 444 suggests that the anticyclonic circulation over Europe was driven by the large scale conversely 445 to what has been suggested by previous studies (Garcia-Herrera et al. 2010). However, it 446 appears that the soil moisture is also an important factor for the occurrence of the 2003 heat 447 wave. First, the precipitation and temperature are better predicted when the soil moisture is 448 initialized (Fig. 7b-c, e-f). Moreover, the results of both experiments show that the soil moisture 449 has a feedback on the atmospheric circulation. Finally, the soil moisture seems important to 450 simulate the cold and moist anomalies in Eastern Europe, which are occurring with the heat 
451 wave over Western Europe. Conversely, the 2010 heat wave is predictable only when the soil

452 moisture is adequately initialized suggesting that the dry soil moisture anomalies at the

453 beginning of spring might have been crucial for the development of the heat wave over Russia.

\section{5. Summary and conclusions}

455 While European climate is hardly predicted by coupled models, many studies have shown the 456 essential role played by soil moisture in this region (Schär et al. 1999, 2004; Fischer et al. 2007; 457 Douville 2010; Seneviratne et al. 2006, 2010, 2013; Quesada et al. 2012). In the framework of 458 the GLACE project, the role of soil-moisture initialization has been assessed at sub-seasonal 459 time scales (Koster et al. 2010, 2011; van den Hurk et al. 2010). Nevertheless, fewer studies 460 evaluated how soil-moisture initialization can affects skill, especially over Europe, at longer time 461 scales (Douville 2010).

462 The present study aims to assess the added value of land-surface initialization for seasonal 463 forecasts. Two sensitivity experiments, consisting in 30 years of 10-member ensemble 464 hindcasts of 4 month length have been run. Both sensitivity experiments have been carried out with the EC-Earth2.3 forecast system initialized in the same way for ocean, atmosphere and sea ice. The difference between both sensitivity experiments resides in the initialization of the soil. While the soil temperature, moisture and snow are initialized with ERA-Land in INIT, these variables are initialized with a climatology of ERA-Land in CLIM.

The comparison of those two experiments for summer (June-to-August average, one-month lead time) shows that land-surface initialization has a positive impact on temperature skill and also, to a lesser extent, on precipitation, which is consistent with previous studies (Koster et al. 2004, 2010; Douville et al. 2010; Materia et al. 2014). This improvement is robust whether the warming trend is considered or not. At regional scale, particularly over Europe, the skill improves in a similar way for $\mathrm{t} 2 \mathrm{~m}$ and a set of associated extreme variables. The improvement occurs up to the last forecast month, which contrasts with the results described in van den Hurk et al. (2010), who found that the improvement goes up to six weeks over Europe. As they found in their study, land initialization can degrade the skill during the second month of the forecast,

479 Land initialization is also crucial for the prediction of the 2010 heat wave over Russia. The 480 prediction of the 2010 event is successful only when the soil moisture is initialized, showing that 481 the dry conditions preceding the heat wave were decisive in the occurrence of the event. 482 Conversely, the 2003 European heat wave is predicted by both experiments, with either a 483 climatological or a realistic land-surface initialization, suggesting that the event was driven by 
484 the large-scale atmospheric circulation. The slightly better skill of the INIT experiment for this 485 event still suggests a positive feedback of dry soil on temperature, consistently with Weisheimer 486 et al. (2011).

487 This study shows an improvement of temperature skill when land is initialized, Nevertheless, 488 while initializing realistically soil moisture improves skill in regions and for variables of low skill, 489 for regions and variables with high skill, the land-surface initialization could lead to a skill 490 degradation, consistently with the findings of Materia et al. (2014). This means that the land491 surface initialization can increase the skill in regions where the original forecast system has no 492 skill but, at the same time, can negatively perturb the large-scale signal or the local conditions 493 in regions of positive skill. A better knowledge of the interaction between the large-scale 494 circulation and the local land-atmosphere coupling as well as an evaluation of the role of the 495 soil-moisture drift on the temperature anomalies simulated is needed to understand the skill 496 degradation. This assessment will require an inspection of the daily evolution of different 497 variables, such as temperature, soil moisture, precipitation and fluxes. The comparison of 498 different soil initialization products and different initialization techniques, such as for example the 499 one known as anomaly initialization, could also help better understanding the processes 500 involved. It is also important determining to what measure the findings of the current study are 501 model dependent. The authors have plans to perform the analysis in a multi-model framework.

502 An interesting result of the study is the ability to predict the 2003 European heat wave even 503 without realistic land-surface initialization from May, suggesting that there is a role for the large504 scale circulation. Deeper analysis are needed to confirm the robustness of this result, first large 505 discrepancies seems to exist between different dataset suggesting that different soil product 506 should be tested for the initialization. Moreover, a large drying which occurs at the beginning of 507 June, new simulation would be needed to know the influence of this drying on the heat wave. 508 The INIT and CLIM simulation will be extended in this purpose. With the help of those extended 509 simulations, the authors will analyze the possible remote forcing of the blocking events over 510 Europe in 2003 and the land-atmosphere feedbacks, which took place that summer.

\section{Acknowledgements}

512 The research leading to these results has received funding from the EU Seventh Framework 513 Programme FP7 (2007-2013) under grant agreements 308378 (SPECS), 282378 (DENFREE)

514 and 607085 (EUCLEIA), and from the Spanish Ministerio de Economía y Competitividad 515 (MINECO) under the project CGL2013-41055-R. We acknowledge the s2dverification R-based 516 package (http://cran.r-project.org/web/packages/s2dverification/index.html). We also thank 
517 ECMWF for providing the ERA-Land initial conditions and computing resources through the 518 SPICCF Special Project.

519 


\section{References}

522 Balmaseda M, Anderson D, Vidard A (2007) Impact of Argo on analyses of the global ocean.

523 Geophys Res Lett 34:L16605. doi: 10.1029/2007GL030452

524

Balmaseda M, Vidard A, Anderson DLT (2008) The ECMWF Ocean Analysis System: ORA-S3.

Mon Weather Rev 136:3018-3034. doi: 10.1175/2008MWR2433.1

Balmaseda M, Anderson D (2009) Impact of initialization strategies and observations on seasonal forecast skill. Geophys Res Lett 36:L01701. doi: 10.1029/2008GL035561

Balmaseda M, Alves O, Arribas A, et al. (2009) Ocean initialization for seasonal forecasts. Oceanography 22:154-159.

Balmaseda M, Mogensen K, Weaver AT (2013) Evaluation of the ECMWF ocean reanalysis system ORAS4. Q J R Meteorol Soc 139:1132-1161. doi: 10.1002/qj.2063

Balsamo G, Beljaars A, Scipal K, et al. (2009) A Revised Hydrology for the ECMWF Model: Verification from Field Site to Terrestrial Water Storage and Impact in the Integrated Forecast System. J Hydrometeorol 10:623-643. doi: 10.1175/2008JHM1068.1

Balsamo, G., et al (2015) ERA-Interim/Land: a global land surface reanalysis data set, Hydrol. Earth Syst. Sci., 19, 389-407, doi:10.5194/hess-19-389-2015 2015.

544 Behera S, Ratnam J V., Masumoto Y, Yamagata T (2012) Origin of extreme summers in 545 Europe: the Indo-Pacific connection. Clim Dyn 41:663-676. doi: 10.1007/s00382-012-1524-8

547 Bellprat O, Kotlarski S, Lüthi D, Schär C (2013) Physical constraints for temperature biases in 548 climate models. Geophys Res Lett 40:4042-4047. doi: 10.1002/grl.50737

550 Cassou C, Terray L, Phillips A (2005) Tropical Atlantic influence on European heat waves. J 551 Clim 2805-2811. 
553 Cohen J, Screen J a., Furtado JC, et al. (2014) Recent Arctic amplification and extreme mid554 latitude weather. Nat Geosci 7:627-637. doi: 10.1038/ngeo2234

556 Challinor AJ, Slingo JM, Wheeler TR, Doblas-Reyes FJ (2005) Probabilistic simulations of crop 557 yield over western India using the DEMETER seasonal hindcast ensembles. Tellus A 57:498558 512. doi: 10.1111/j.1600-0870.2005.00126.x

559

Christensen JH, Christensen OB (2007) A summary of the \{PRUDENCE\} model projections of changes in $\{$ E\}uropean climate by the end of this century. Clim Change 81:7-30.

Dee DP, Berrisford P, Poli P, Fuentes M (2009) ERA-Interim for climate monitoring. ECMWF Newsletter 119: 5-6.

565

Dee DP, Uppala SM, Simmons a. J, et al. (2011) The ERA-Interim reanalysis: configuration and performance of the data assimilation system. Q J R Meteorol Soc 137:553-597. doi: 10.1002/qj.828

Dirmeyer P (2005) The land surface contribution to the potential predictability of boreal summer season climate. J Hydrometeorol 6:618-632. doi: 10.1175/JHM444.1

Doblas-Reyes FJ, Hagedorn R, Palmer TN, Morcrette J-J (2006) Impact of increasing greenhouse gas concentrations in seasonal ensemble forecasts. Geophys Res Lett 33:L07708. doi: 10.1029/2005GL025061

Doblas-Reyes FJ, García-Serrano J, Lienert F, et al (2013) Seasonal climate predictability and forecasting: Status and prospects. Wiley Interdiscip Rev Clim Chang 4:245-268. doi: 10.1002/wcc. 217 heat wave? Geophys Res Lett 38:1-5. doi: 10.1029/2010GL046582 
587 Eade R, Hamilton E, Smith DM, et al. (2012) Forecasting the number of extreme daily events 588 out to a decade ahead. J Geophys Res Atmos 117:D21110. doi: 10.1029/2012JD018015

Feudale L, Shukla J (2011) Influence of sea surface temperature on the European heat wave of 2003 summer. Part I: an observational study. Clim Dyn 36:1691-1703. doi: 10.1007/s00382010-0788-0

Feudale L, Shukla J (2011) Influence of sea surface temperature on the European heat wave of 2003 summer. Part II: a modeling study. Clim Dyn 36:1705-1715. doi: 10.1007/s00382-0100789-z

Fichefet T, Maqueda Morales MA (1997) Sensitivity of a global sea ice model to the treatment of ice thermodynamics and dynamics. J Geophys Res 102:12609. doi: 10.1029/97JC00480

Fischer EM, Seneviratne SI, Lüthi D, Schär C (2007) Contribution of land-atmosphere coupling to recent European summer heat waves. Geophys Res Lett 34:L06707. doi: 10.1029/2006GL029068

604

Fischer EM, Seneviratne SI, Vidale PL, et al (2007b) Soil Moisture-Atmosphere Interactions during the 2003 European Summer Heat Wave. J Clim 20:5081-5099. doi: 10.1175/JCLI4288.1

Fischer EM (2014) Climate science: Autopsy of two mega-heatwaves. Nat Geosci 7:332-333. doi: $10.1038 /$ ngeo2148

Fosser G, Khodayar S, Berg P (2014) Benefit of convection permitting climate model 612 simulations in the representation of convective precipitation. Clim Dyn 44:45-60. doi: 10.1007/s00382-014-2242-1

615 García-Herrera R, Díaz J, Trigo RM, et al. (2010) A Review of the European Summer Heat 616 Wave of 2003. Crit Rev Environ Sci Technol 40:267-306. doi: 10.1080/10643380802238137

618 García- Morales M, Dubus L (2007) Forecasting precipitation for hydroelectric power 619 management: how to exploit GCM's seasonal ensemble forecasts. Int J Climatol 1705:1691620 1705. doi: 10.1002/joc 
622 Guemas V, Doblas-Reyes FJ, Mogensen K, et al. (2014) Ensemble of sea ice initial conditions 623 for interannual climate predictions. Clim Dyn. doi: 10.1007/s00382-014-2095-7

625 Hamilton E, Eade R, Graham RJ, et al. (2012) Forecasting the number of extreme daily events 626 on seasonal timescales. J Geophys Res 117:D03114. doi: 10.1029/2011JD016541

Hazeleger W, Wang X, Severijns C, et al. (2011) EC-Earth 8.2: description and validation of a 629 new seamless earth system prediction model. Clim Dyn 39:2611-2629. doi: 10.1007/s00382011-1228-5

Hirschi M, Seneviratne SI, Alexandrov V, et al. (2011) Observational evidence for soil-moisture impact on hot extremes in southeastern Europe. Nat Geosci 4:17-21. doi: 10.1038/ngeo1032

Hourdin F, Grandpeix J-Y, Rio C, et al. (2012) LMDZ5B: the atmospheric component of the IPSL climate model with revisited parameterizations for clouds and convection. Clim Dyn 40:2193-2222. doi: 10.1007/s00382-012-1343-y

Jaeger EB, Seneviratne SI (2010) Impact of soil moisture-atmosphere coupling on European climate extremes and trends in a regional climate model. Clim Dyn 36:1919-1939. doi: $10.1007 / \mathrm{s} 00382-010-0780-8$

Kim H-M, Webster PJ, Curry J a. (2012) Seasonal prediction skill of ECMWF System 4 and

644 NCEP CFSv2 retrospective forecast for the Northern Hemisphere Winter. Clim Dyn 39:2957645 2973. doi: 10.1007/s00382-012-1364-6

646

647 Kutiel H, Benaroch Y (2002) North Sea-Caspian Pattern (NCP)-an upper level atmospheric 648 teleconnection affecting the Eastern Mediterranean: Identification and definition. Theor Appl 649 Climatol 28:17-28. doi: 10.1007/s704-002-8205-x

651 Koster RD, Suarez MJ, Liu P, et al (2004) Realistic Initialization of Land Surface States: Impacts 652 on Subseasonal Forecast Skill. J Hydrometeorol 5:1049-1063. 
654 Koster RD, Mahanama SPP, Yamada TJ, et al (2010) Contribution of land surface initialization 655 to subseasonal forecast skill: First results from a multi-model experiment. Geophys Res Lett 656 37:L02402. doi: 10.1029/2009GL041677

658 Koster RD, Mahanama SPP, Yamada TJ, et al (2011) The Second Phase of the Global Land659 Atmosphere Coupling Experiment: Soil Moisture Contributions to Subseasonal Forecast Skill. J 660 Hydrometeorol 12:805-822. doi: 10.1175/2011JHM1365.1

662 Landman W a., Beraki A (2012) Multi-model forecast skill for mid-summer rainfall over southern 663 Africa. Int J Climatol 32:303-314. doi: 10.1002/joc.2273

664

665 Lee S-S, Lee J-Y, Ha K-J, et al. (2010) Deficiencies and possibilities for long-lead coupled 666 climate prediction of the Western North Pacific-East Asian summer monsoon. Clim Dyn 667 36:1173-1188. doi: 10.1007/s00382-010-0832-0

668

MacLachlan C, Arribas A, Peterson KA, et al. (2014) Global Seasonal Forecast System version 5 (GloSea5): a high resolution seasonal forecast system. Q J R Meteorol Soc. doi: 10.1002/qj.2396

672

673 Madec G (2008) NEMO ocean engine. Note du Pole de modelisation, Institut Pierre-Simon 674 Laplace (IPSL) No 27. ISSN No 1288-1619 Mason S, Mimmack G (1992) The use of bootstrap confidence intervals for the correlation coefficient in climatology. Theor Appl Climatol 45:229-233. Materia S, Borrelli A, Bellucci A, et al (2014) Impact of Atmosphere and Land Surface Initial 680 Conditions on Seasonal Forecasts of Global Surface Temperature. J Clim 27:9253-9271. doi: 10.1175/JCLI-D-14-00163.1

682

683 Miralles DG, Teuling AJ, Heerwaarden CC Van (2014) Mega-heatwave temperatures due to 684 combined soil desiccation and atmospheric heat accumulation. Nat Geosci 7:345-349. doi: $68510.1038 /$ ngeo2141 
687 Orsolini YJ, Kvamstø NG (2009) Role of Eurasian snow cover in wintertime circulation: Decadal 688 simulations forced with satellite observations. J Geophys Res 114:D19108. doi: 689 10.1029/2009JD012253

690

Rene Orth, Seneviratne SI (2015) Introduction of a simple-model-based land surface dataset for 692 Europe. Environ Res Lett 10:044012. doi: 10.1088/1748-9326/10/4/044012

Palmer TN, Shutts GJ, Hagedorn R, et al. (2005) Representing Model Uncertainty in Weather 695 and Climate Prediction. Annu Rev Earth Planet Sci 33:163-193. doi: 10.1146/annurev.earth.33.092203.122552

Palmer TN, Doblas-Reyes FJ, Hagedorn R, Weisheimer A (2005b) Probabilistic prediction of climate using multi-model ensembles: from basics to applications. Philos Trans $R$ Soc Lond $B$ Biol Sci 360:1991-8. doi: 10.1098/rstb.2005.1750

Pepler AS, Diaz L, Karthik Kashinath K, et al, The ability of a multi-model seasonal forecasting ensemble to forecast the seasonal distribution of daily extremes. Weather and Climate Extremes (submitted)

Phelps M, Kumar A, O'Brien J (2004) Potential predictability in the NCEP CPC dynamical seasonal forecast system. J Clim 17:3775-3785.

Quesada B, Vautard R, Yiou P, et al. (2012) Asymmetric European summer heat predictability from wet and dry southern winters and springs. Nat Clim Chang 2:736-741. doi: 10.1038/nclimate 1536

Reinhold B, Pierrehumbert R (1982) Dynamics of weather regimes: Quasi-stationary waves and blocking. Mon. Weather Rev.

716 Rodwell M, Rowell D, Folland C (1999) Oceanic forcing of the wintertime North Atlantic 717 Oscillation and European climate. Nature 398:25-28.

719 Rogers J (1997) North Atlantic storm track variability and its association to the North Atlantic 720 Oscillation and climate variability of northern Europe. J Clim 10:1635-1647. 
722 Saha S, Moorthi S, Pan H-L, et al. (2010) The NCEP Climate Forecast System Reanalysis. Bull 723 Am Meteorol Soc 91:1015-1057. doi: 10.1175/2010BAMS3001.1

Scaife A a., Copsey D, Gordon C, et al. (2011) Improved Atlantic winter blocking in a climate model. Geophys Res Lett 38:L23703. doi: 10.1029/2011GL049573

Schär C, Lüthi D, Beyerle U, Heise E (1999) The soil-precipitation feedback: A process study with a regional climate model. J Clim 12:722-741.

Seneviratne SI, Lüthi D, Litschi M, Schär C (2006) Land-atmosphere coupling and climate change in Europe. Nature 443:205-9. doi: 10.1038/nature05095

Seneviratne SI, Corti T, Davin EL, et al (2010) Investigating soil moisture-climate interactions in 735 a changing climate: A review. Earth-Science Rev 99:125-161. doi: 10.1016/j.earscirev.2010.02.004

Seneviratne S, Wilhelm M, Stanelle T, et al. (2013) Impact of soil moisture- climate feedbacks on CMIP5 projections: First results from the GLACE- CMIP5 experiment. Geophys Res Lett 40:5212-5217. doi: 10.1002/grl.50956

742 Seneviratne SI, Lehner I, Gurtz J, et al. (2012) Swiss prealpine Rietholzbach research 743 catchment and lysimeter: 32 year time series and 2003 drought event. Water Resour Res 48:1744 20. doi: $10.1029 / 2011$ WR011749

Shaman J, Tziperman E (2011) An Atmospheric Teleconnection Linking ENSO and

747 Southwestern European Precipitation. J Clim 24:124-139. doi: 10.1175/2010JCLI3590.1

749 Shukla J, Kinter III JL (2006) Predictability of seasonal climate variations: A pedagogical review.

750 Predictability in Weather and Climate, 306-341.

752 Steiger (1980) Tests for comparing elements of a correlation matrix. doi: 10.1037/0033$753 \quad 2909.87 .2 .245$ 
Valcke S (2006) OASIS3 user guide (prism_2-5). PRISM support initiative report 3, pp 64

van den Hurk BJJM, et al (2000) Offline validation of the ERA40 surface scheme. European

758 Centre for Medium-Range Weather Forecasts Technical Memorandum 295. Available from

759 http://nwmstest.ecmwf.int/publications/library/do/references/show?id=83838

van den Hurk BJJM, Doblas-Reyes F, Balsamo G, et al (2010) Soil moisture effects on seasonal temperature and precipitation forecast scores in Europe. Clim Dyn 38:349-362. doi: 10.1007/s00382-010-0956-2

van Oldenborgh GJ, Doblas Reyes FJ, Drijfhout SS, Hawkins E (2013) Reliability of regional climate model trends. Environ Res Lett 8:014055. doi: 10.1088/1748-9326/8/1/014055

von Storch H, Zwiers FW (2001) Statistical Analysis in Climate Research. Cambridge University Press, $484 \mathrm{pp}$.

Wang A, Bohn TJ, Mahanama SP, et al. (2009) Multimodel Ensemble Reconstruction of Drought over the Continental United States. J Clim 22:2694-2712. doi: 10.1175/2008JCLI2586.1

774

Wang E, Xu J, Jiang Q, Austin J (2008) Assessing the spatial impact of climate on wheat productivity and the potential value of climate forecasts at a regional level. Theor Appl Climatol 95:311-330. doi: 10.1007/s00704-008-0009-5

Wang G, Dolman a. J, Alessandri a. (2011) A summer climate regime over Europe modulated by the North Atlantic Oscillation. Hydrol Earth Syst Sci 15:57-64. doi: 10.5194/hess-15-57-2011

Whan K, Zscheischler J, Orth R, et al. (2015) Impact Of Soil Moisture On Extreme Maximum Temperatures In Europe. Weather Clim Extrem 1-11. doi: 10.1016/j.wace.2015.05.001

Weisheimer A, Doblas-Reyes FJ, Jung T, Palmer TN (2011) On the predictability of the extreme summer 2003 over Europe. Geophys Res Lett 38. doi: 10.1029/2010GL046455

\section{Figure captions}


Fig. 1: a Correlation of the ensemble mean $\mathrm{t} 2 \mathrm{~m}$ averaged in JJA (one-month lead time) in the CLIM experiment. The dots mark the areas where the correlation is significant at the $95 \%$ confidence level. $\mathbf{b}$ Same as a, but for precipitation. c Difference of correlation of the ensemble mean between the INIT and CLIM experiments for the t2m in JJA. The dots mark the areas where the difference of correlation is significant at the $95 \%$ confidence level. $\mathbf{d}$ Same as $\mathbf{c}$ but

794 for precipitation.

Fig. 2: a Scatter plot of the difference of correlation of the JJA t2m (one-month lead time) between INIT and CLIM against the correlation of the JJA t2m in CLIM over the the Northern Hemisphere land grid points. The numbers in the corners correspond to the percentage of grid points in the respective quadrants. The grey dots correspond to the values in the grid points where neither the correlation in CLIM, INIT, nor the difference of correlation between INIT and CLIM is significant. The black dots represent the points where the correlation is significant at 95\% confidence level in both CLIM and INIT, the orange dots the points where the correlation is significant at $95 \%$ confidence level in INIT but not in CLIM, the light blue dots to the points where the correlation is significant at 95\% confidence level in CLIM but not in INIT and the red (dark blue) dots to the points where the correlation difference is significantly positive (negative) at $95 \%$ confidence level. b Same as a, but in the tropics. c Same as a, but in the Southern Hemisphere (without Antarctica). d Same as a, but over the whole globe. The $\mathbf{e}, \mathbf{f}, \mathbf{g}$ and $\mathbf{h}$ panels show the equivalent results for precipitation.

Fig. 3: As in Fig. 1, but with the correlation computed using the residual of the regression of the temperature and precipitation anomalies on the global mean temperature.

Fig. 4: Correlation of the ensemble mean in JJA (one-month lead time) in CLIM, for a q90 of Tx, 814 b number of warm days, $\mathbf{c}$ q90 of Tn, $\mathbf{d}$ number of warm nights, $\mathbf{e}$ the $\mathbf{q} 10$ of $\mathrm{Tn}$ and $\mathbf{f}$ number of 815 cold nights. The dots mark the areas where the correlation is statistically significant with a $95 \%$ 816 confidence level. Difference of correlation between INIT and in CLIM in JJA, for $\mathbf{g}$ q90 of Tx, $\mathbf{h}$ 817 number of warm days, $\mathbf{i}$ q90 of Tn, $\mathbf{j}$ number of warm nights, $\mathbf{k}$ the q10 of $\mathrm{Tn}$ and $\mathbf{I}$ number of 818 cold nights. The dots mark the areas where the difference of correlation is significant at $95 \%$ 819 confidence level and the correlation has been computed using the detrended anomalies.

Fig. 5: a Mean spatial anomaly correlation coefficient (MACC) calculated for the ensemblemean hindcasts of CLIM (plain line) and INIT (dotted line) over the land in Europe (10ㄴ $40^{\circ} \mathrm{E}-$ 
$35^{\circ} \mathrm{N} 75^{\circ} \mathrm{N}$ ) for the monthly mean $\mathrm{t} 2 \mathrm{~m}$ (black), the q90 of Tx (red), the q90 of Tn (pink), the q10 of Tn (purple), the number warm days (orange), the number of warm nights (green) and the number of cold days (light blue). The MACC is calculated on detrended anomalies. The solid (open) dots mark the values significant at 95\% level in INIT (CLIM), estimated with a bootstrap over of 100 drawings. b Same as a but for the difference of the MACC between INIT and CLIM. None of the difference of MACC is significant at $95 \%$ level, estimated with a bootstrap of 100 drawings.

Fig. 6: a Difference of correlation between the INIT and CLIM experiments for the temperature

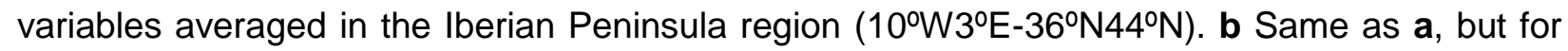
France $\left(5^{\circ} \mathrm{W} 5^{\circ} \mathrm{E}-44^{\circ} \mathrm{N} 50^{\circ} \mathrm{N}\right)$, c central-Europe $\left(2^{\circ} \mathrm{W} 16^{\circ} \mathrm{E}-48^{\circ} \mathrm{N} 55^{\circ} \mathrm{N}\right)$, d Scandinavia (5트을 $\left.55^{\circ} \mathrm{N} 70^{\circ} \mathrm{N}\right)$, e the Alps ( $\left.5^{\circ} \mathrm{E} 15^{\circ} \mathrm{E}-44^{\circ} \mathrm{N} 48^{\circ} \mathrm{N}\right)$, $f$ the Mediterranean area $\left(3^{\circ} \mathrm{E} 25^{\circ} \mathrm{E}-36^{\circ} \mathrm{N} 44^{\circ} \mathrm{N}\right)$ and

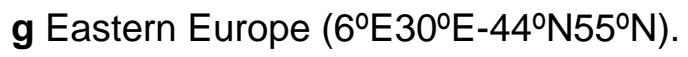

Fig. 7: a Observed anomalies of t2m for 2003 JJA (one-month lead time) mean (K). The dots indicate the area where the anomaly is in the upper quintile (estimated over 1981-2010). $b$ Odds in CLIM for t2m. The odds are the ratio between the probability for the anomalies to be in the upper quintile, the interquintile range or the lower quintile and with the climatological probability of these three categories $(20 \%, 60 \%$ and $20 \%$, respectively). Each point is attributed to the category corresponding to the highest odds ratio. If the point is attributed to the interquintile range or if there is no category assigned (the categories with two highest odds ratio have an equal value) the point is drawn in white. If the point is attributed to the lower/upper quintile category, the corresponding odds ratio is plotted with the left/right color scale.c Same as $\mathbf{b}$, but for INIT. d Observed anomalies of precipitation for $2003 \mathrm{JJA}$ mean ( $\mathrm{mm} /$ day). The dots indicate the area where the anomaly is in the lower quintile for the 1981-2010 period. $\mathbf{e}$ same as $\mathbf{b}$, but for precipitation. $\mathbf{f}$ Same as $\mathbf{c}$, but for precipitation. $\mathbf{g}, \mathbf{h}$, i same as $\mathbf{a}, \mathbf{b}, \mathbf{c}$, but for geopotential height at $500 \mathrm{hPa}(\mathrm{m}) . \mathbf{j}, \mathbf{k}, \mathbf{I}$ same as $\mathbf{a}, \mathbf{b}, \mathbf{c}$, but for monthly mean of 6 hourly SLP (hPa). $\mathbf{m}, \mathbf{n}$, o same as $\mathbf{d}, \mathbf{e}, \mathbf{f}$, but for the vertically integrated volume fraction of water in soil $\left(\mathrm{m}^{3} / \mathrm{m}^{3}\right)$.

Fig. 8: Same as Fig. 7, but for JJA (one-month lead time) 2010.

Fig.9: a Standardized anomalies with respect to the daily climatology computed over 1981-2010 of ERA-Land for May 1st 2003. b Evolution of the daily anomalies of summer 2003 averaged in the black box of a (5W20E-43N55N) in black for ERA-Land, in blue for the ensemble mean of CLIM and in red for the ensemble mean of INIT. c Same as a but for May 1st 2010. d Same as 
858 b but for the box drawn on c (25E55E-45N60N) during summer 2010. For all the panel the unit 859 is $\mathrm{m}^{3} / \mathrm{m}^{3}$. 


\section{Figures}

a) t2m: CLIM

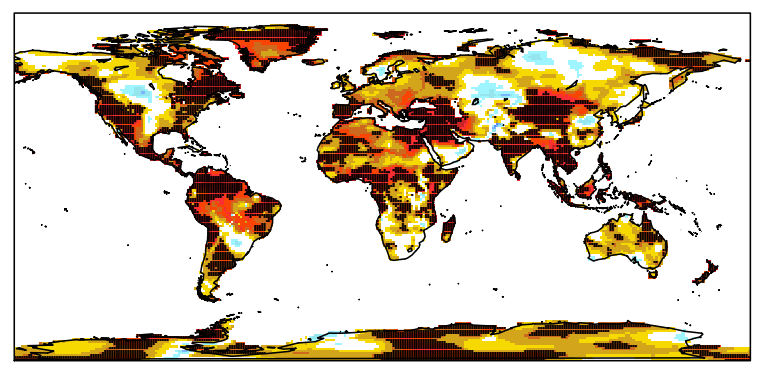

c) t2m: INIT-CLIM

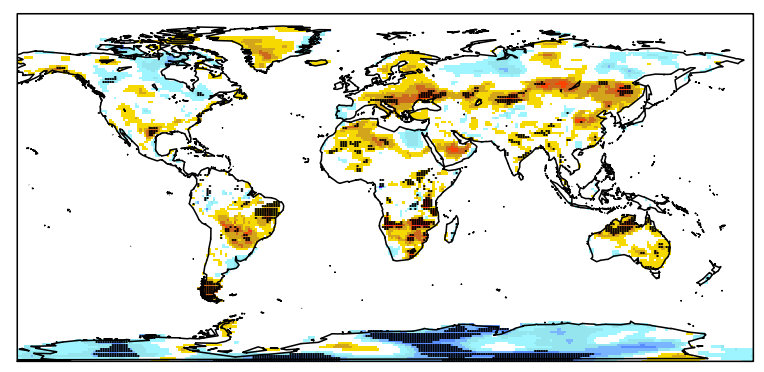

b) precip: CLIM

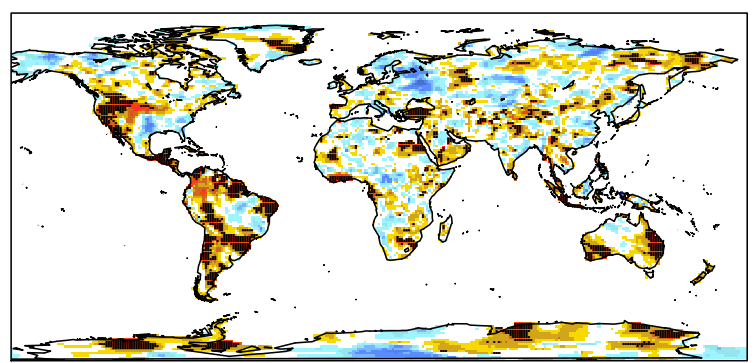

d) precip: INIT-CLIM

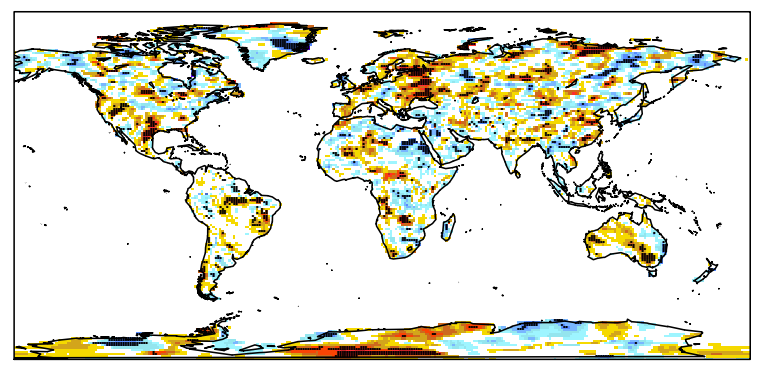

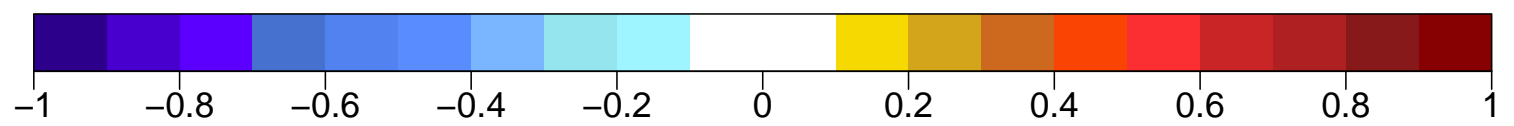

Fig. 1: a Correlation of the ensemble mean t2m averaged in JJA (one-month lead time) in the CLIM experiment. The dots mark the areas where the correlation is significant at the $95 \%$ confidence level. b Same as a, but for precipitation. c Difference of correlation of the ensemble mean between the INIT and CLIM experiments for the $\mathrm{t} 2 \mathrm{~m}$ in JJA. The dots mark the areas where the difference of correlation is significant at the $95 \%$ confidence level. $\mathbf{d}$ Same as $\mathbf{c}$ but for precipitation. 

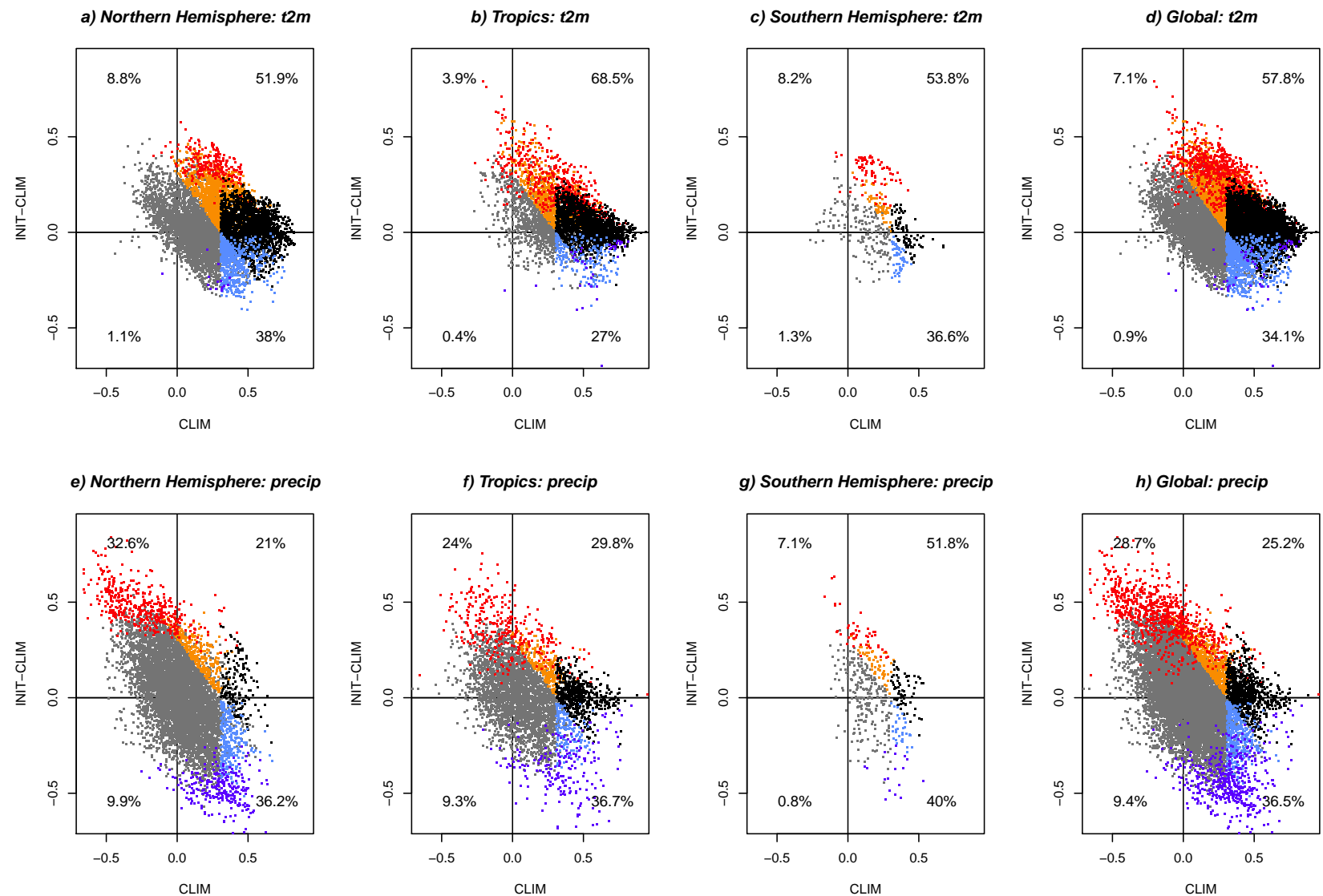

Fig. 2: a Scatter plot of the difference of correlation of the JJA t2m (one-month lead time) between INIT and CLIM against the correlation of the JJA t2m in CLIM over the the Northern Hemisphere land grid points. The numbers in the corners correspond to the percentage of grid points in the respective quadrants. The grey dots correspond to the values in the grid points where neither the correlation in CLIM, INIT, nor the difference of correlation between INIT and CLIM is significant. The black dots represent the points where the correlation is significant at 95\% confidence level in both CLIM and INIT, the orange dots the points where the correlation is significant at $95 \%$ confidence level in INIT but not in CLIM, the light blue dots to the points where the correlation is significant at 95\% confidence level in CLIM but not in INIT and the red (dark blue) dots to the points where the correlation difference is significantly positive (negative) at $95 \%$ confidence level. b Same as a, but in the tropics. c Same as a, but in the Southern Hemisphere (without Antarctica). d Same as $\mathbf{a}$, but over the whole globe. The $\mathbf{e}, \mathbf{f}, \mathbf{g}$ and $\mathbf{h}$ panels show the equivalent results for precipitation. 
a) t2m: CLIM

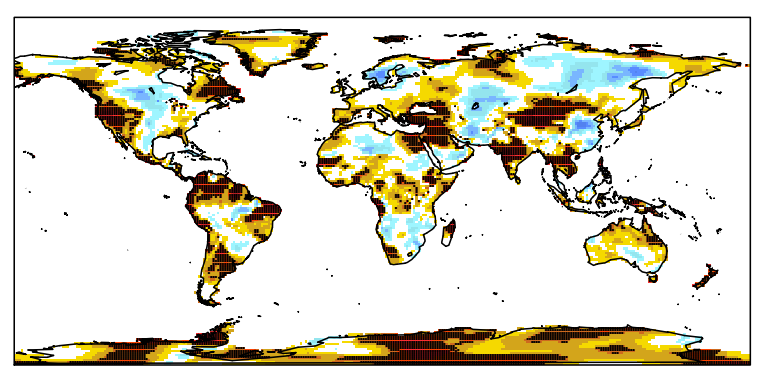

c) t2m: INIT-CLIM
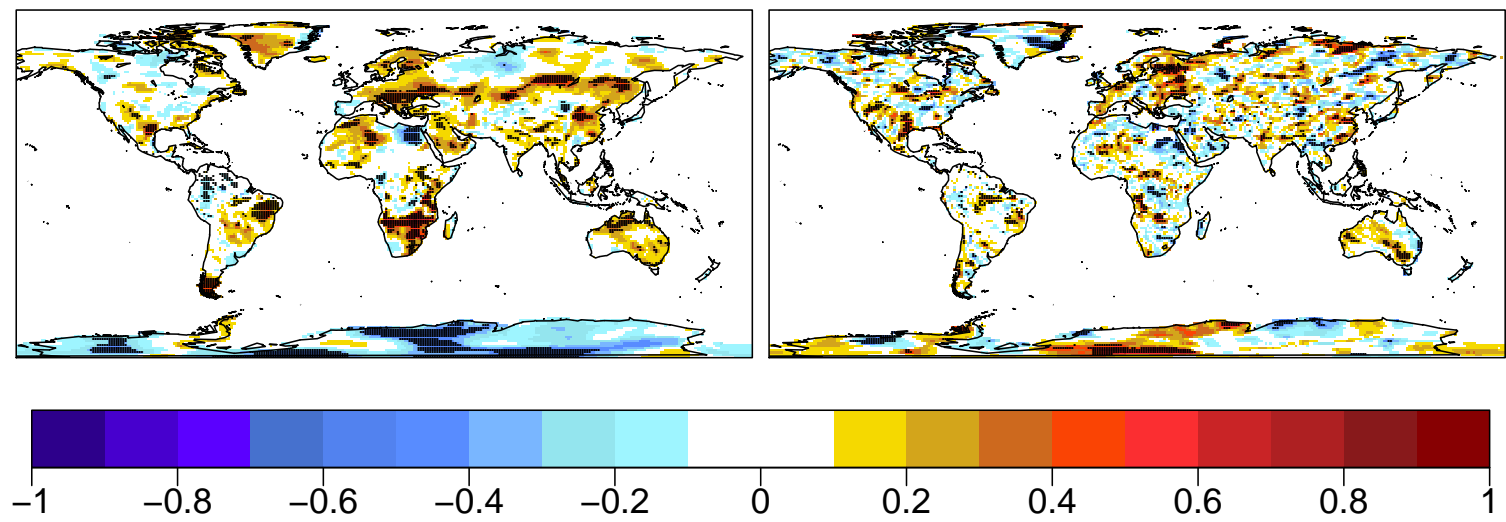

Fig. 3: As in Fig. 1, but with the correlation computed using the residual of the regression of the temperature and precipitation anomalies on the global mean temperature. b) precip: CLIM

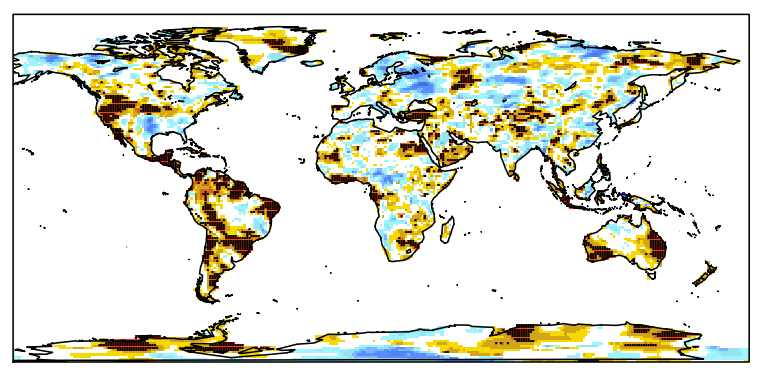

d) precip: INIT-CLIM

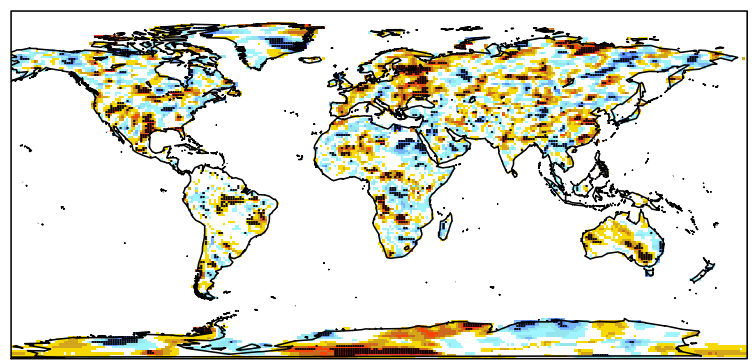

0.8 

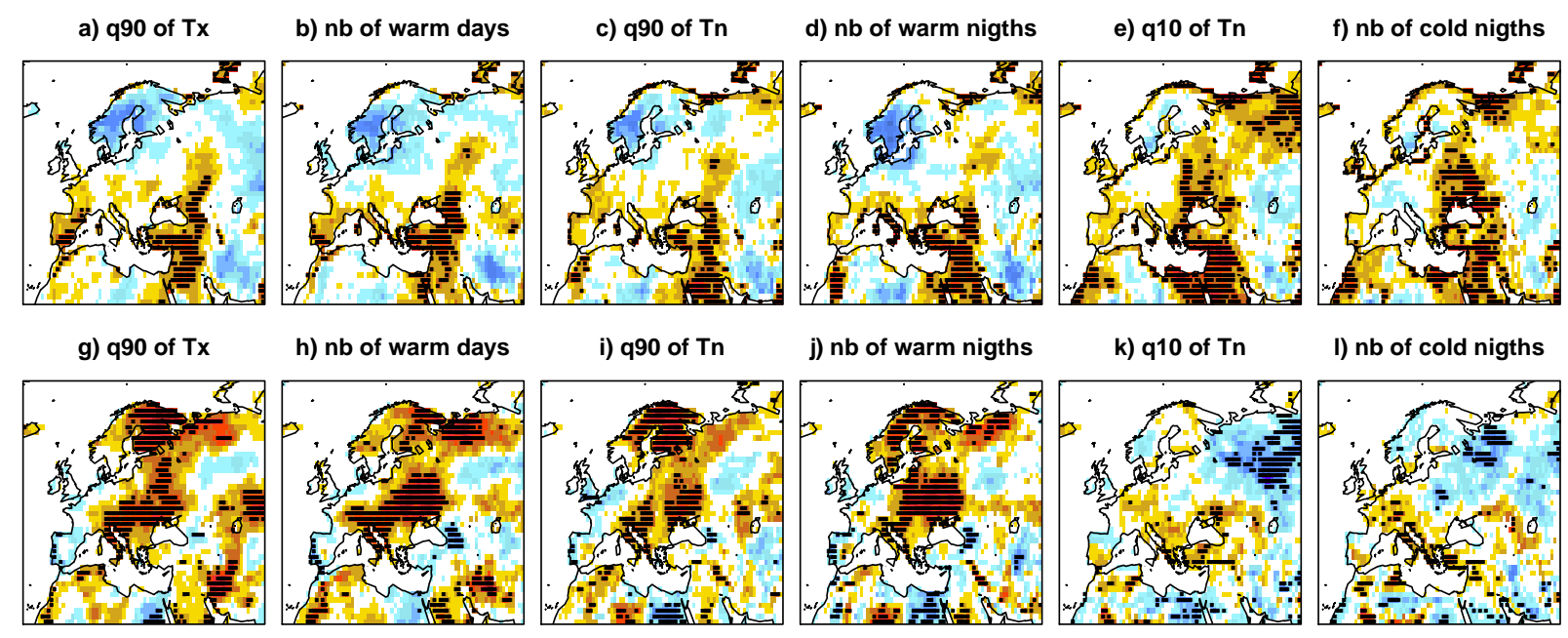

j) nb of warm nigths
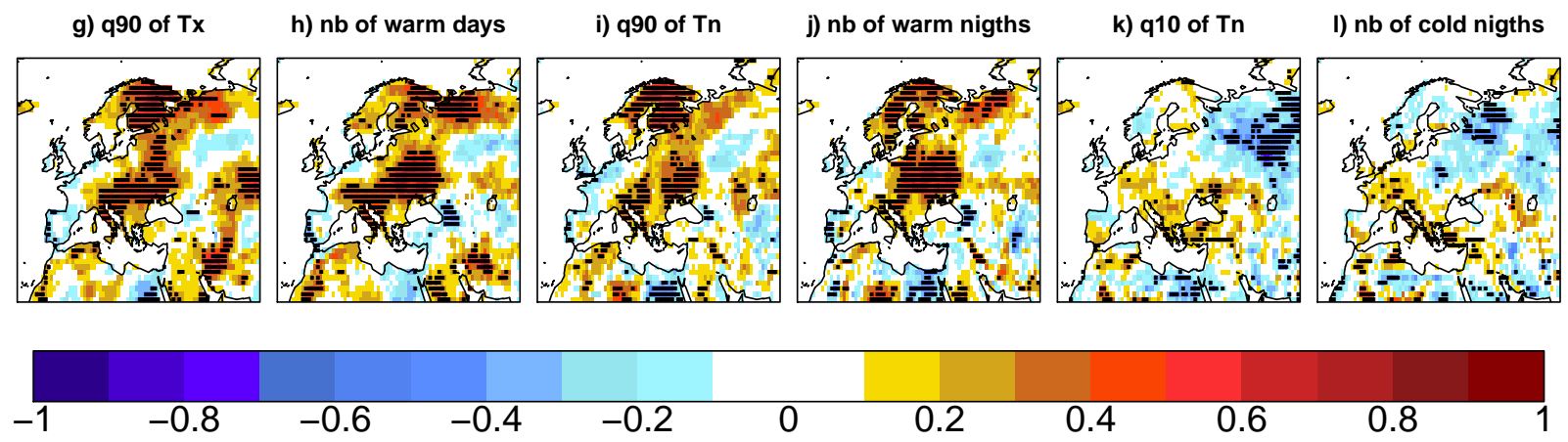

Fig. 4: Correlation of the ensemble mean in JJA (one-month lead time) in CLIM, for a q90 of Tx, b number of warm days, $\mathbf{c}$ q90 of Tn, $\mathbf{d}$ number of warm nights, e the q10 of Tn and $\mathbf{f}$ number of cold nights. The dots mark the areas where the correlation is statistically significant with a 95\% confidence level. Difference of correlation between INIT and in CLIM in JJA, for g q90 of Tx, h number of warm days, $\mathbf{i}$ q90 of Tn, $\mathbf{j}$ number of warm nights, $\mathbf{k}$ the q10 of Tn and $\mathbf{l}$ number of cold nights. The dots mark the areas where the difference of correlation is significant at $95 \%$ confidence level and the correlation has been computed using the detrended anomalies. 
a) MACC of t2m over Europe

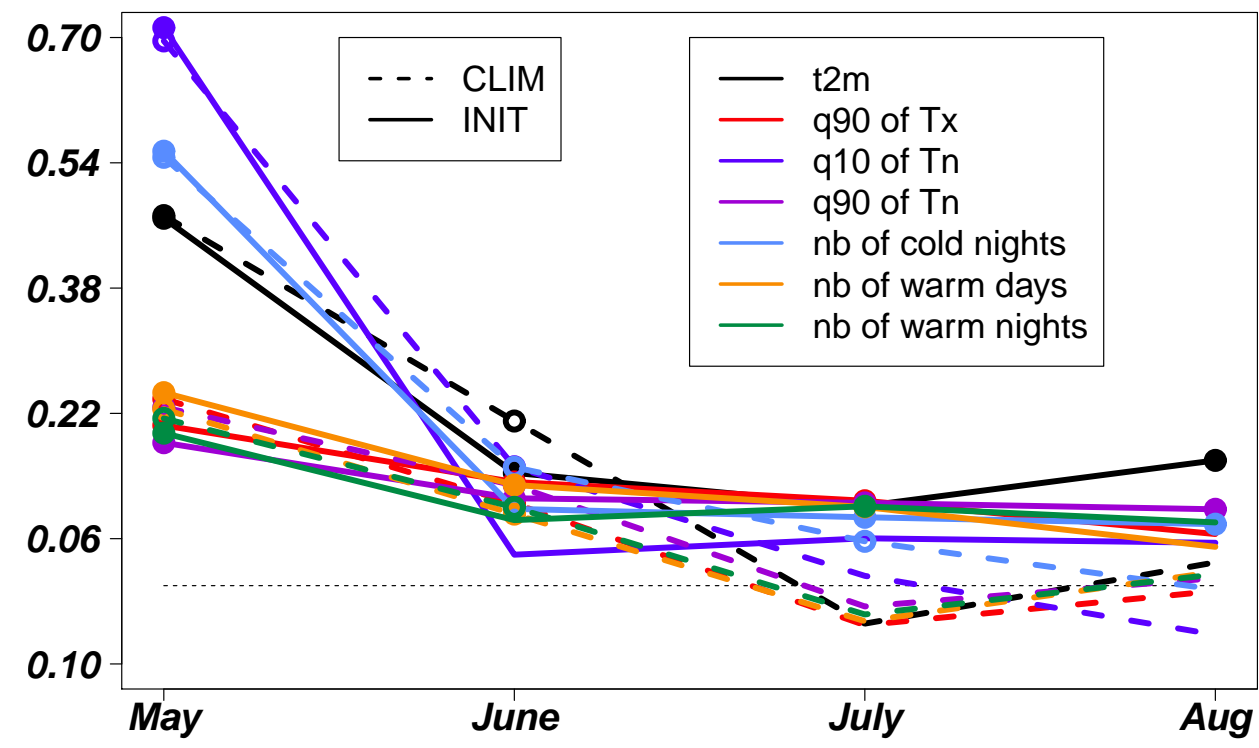

b) MACC of t2m over Europe

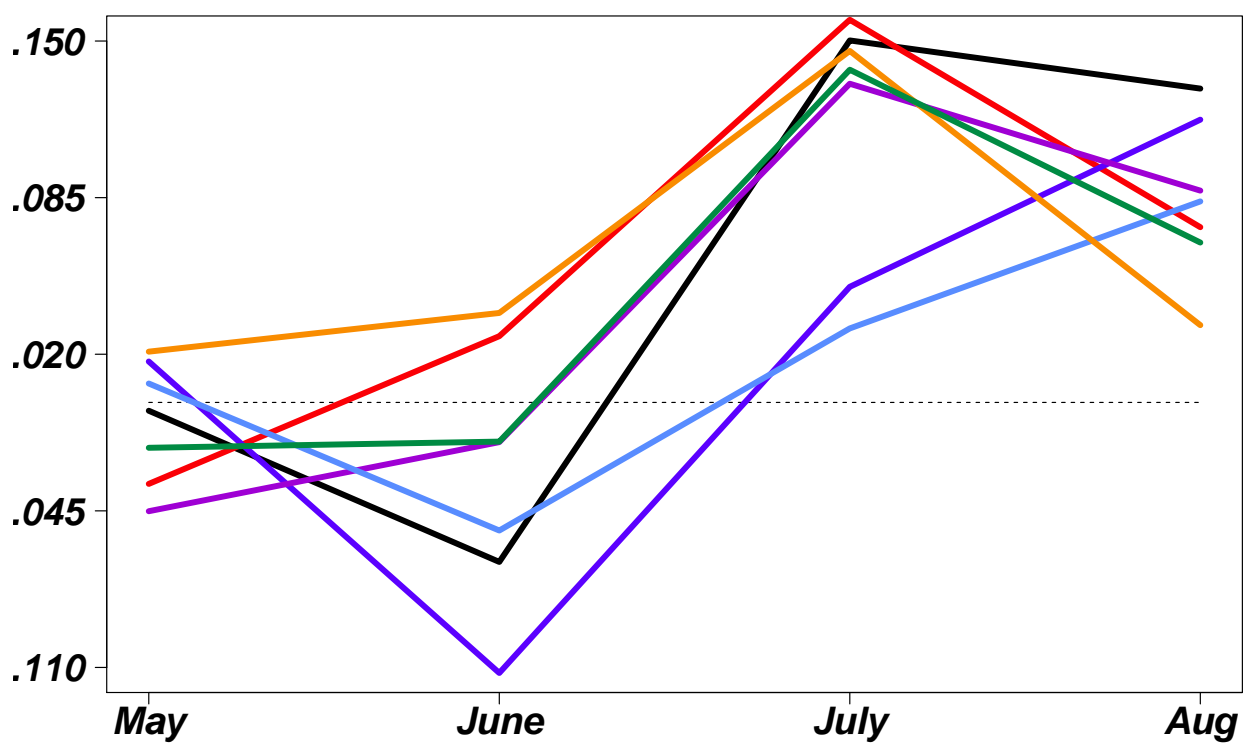

Fig. 5: a Mean spatial anomaly correlation coefficient (MACC) calculated for the ensemblemean hindcasts of CLIM (plain line) and INIT (dotted line) over the land in Europe $\left(10^{\circ} \mathrm{W} 40^{\circ} \mathrm{E}\right.$ $35^{\circ} \mathrm{N} 75^{\circ} \mathrm{N}$ ) for the monthly mean t2m (black), the q90 of Tx (red), the q90 of Tn (pink), the q10 of Tn (purple), the number warm days (orange), the number of warm nights (green) and the number of cold days (light blue). The MACC is calculated on detrended anomalies. The solid (open) dots mark the values significant at 95\% level in INIT (CLIM), estimated with a bootstrap over of 100 drawings. b Same as a but for the difference of the MACC between INIT and CLIM. 

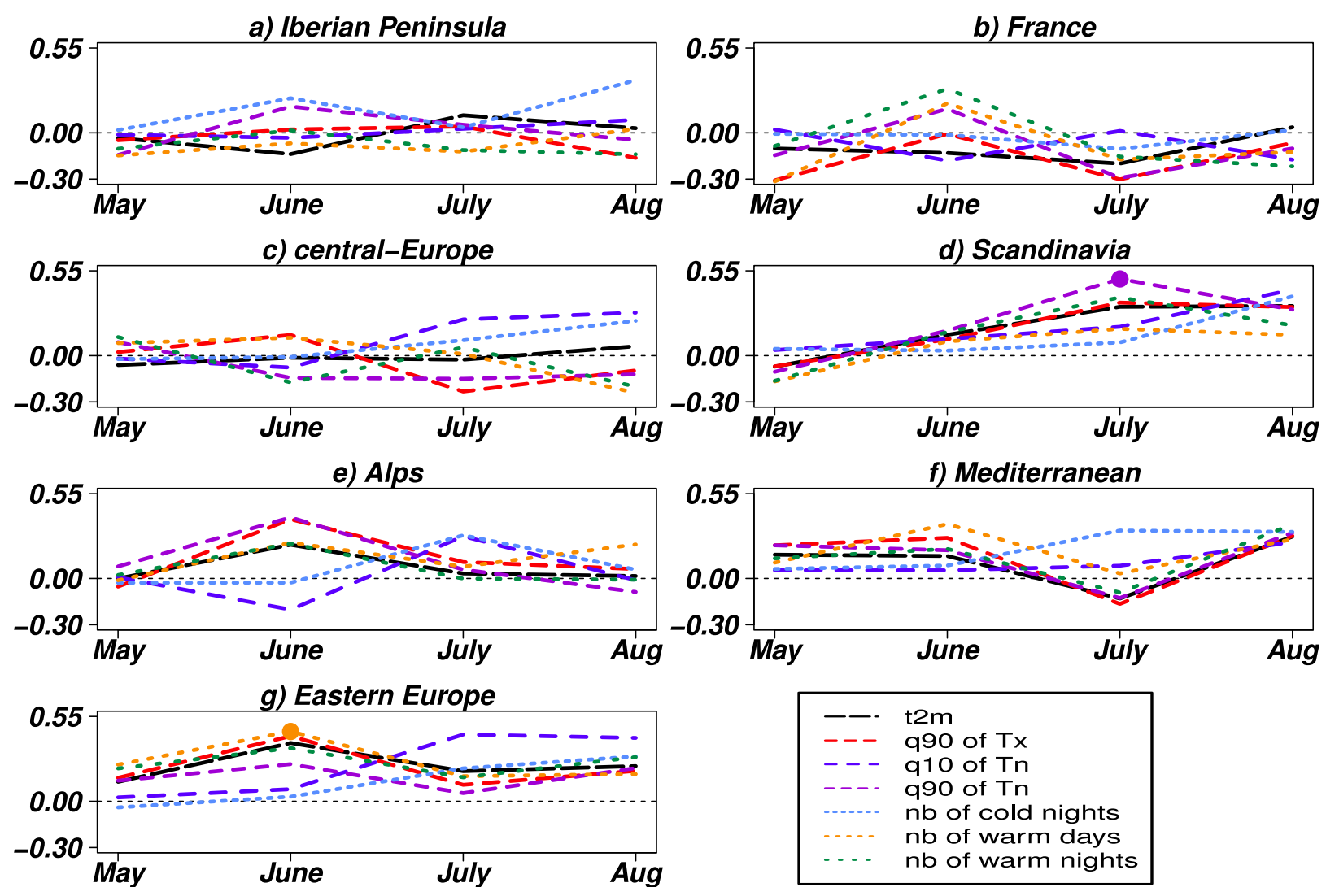

Fig. 6: a Difference of correlation between the INIT and CLIM experiments for the temperature variables averaged in the Iberian Peninsula region $\left(10^{\circ} \mathrm{W} 3^{\circ} \mathrm{E}-36^{\circ} \mathrm{N} 44^{\circ} \mathrm{N}\right)$. $\mathbf{b}$ Same as $\mathbf{a}$, but for France $\left(5^{\circ} \mathrm{W} 5^{\circ} \mathrm{E}-44^{\circ} \mathrm{N} 50^{\circ} \mathrm{N}\right)$, c central-Europe $\left(2^{\circ} \mathrm{W} 16^{\circ} \mathrm{E}-48^{\circ} \mathrm{N} 55^{\circ} \mathrm{N}\right)$, d Scandinavia $\left(5^{\circ} \mathrm{E} 30^{\circ} \mathrm{E}-\right.$ $\left.55^{\circ} \mathrm{N} 70^{\circ} \mathrm{N}\right)$, e the Alps $\left(5^{\circ} \mathrm{E} 15^{\circ} \mathrm{E}-44^{\circ} \mathrm{N} 48^{\circ} \mathrm{N}\right)$, f the Mediterranean area $\left(3^{\circ} \mathrm{E} 25^{\circ} \mathrm{E}-36^{\circ} \mathrm{N} 44^{\circ} \mathrm{N}\right)$ and $\mathrm{g}$ Eastern Europe $\left(6^{\circ} \mathrm{E} 30^{\circ} \mathrm{E}-44^{\circ} \mathrm{N} 55^{\circ} \mathrm{N}\right)$. 
a) t2m: ERAint

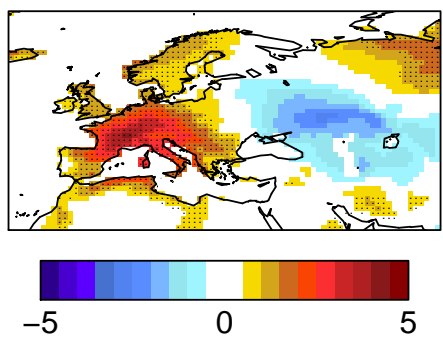

d) precip: ERAint

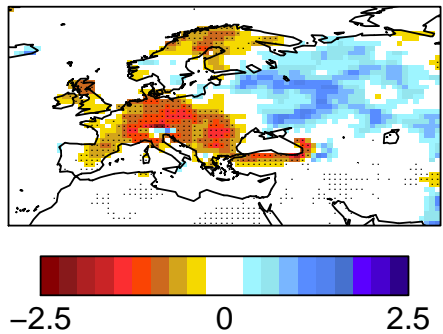

g) z500: ERAint

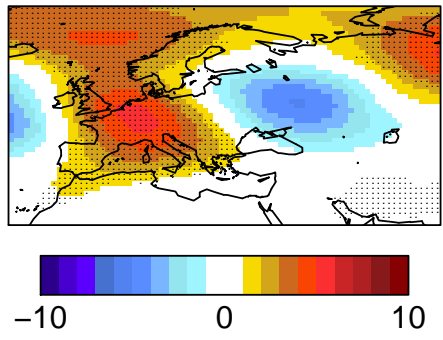

j) SLP: ERAint

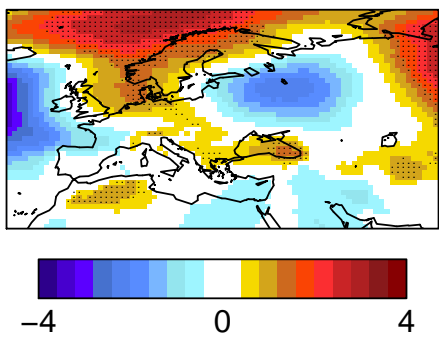

m) soil moisture: ERAland

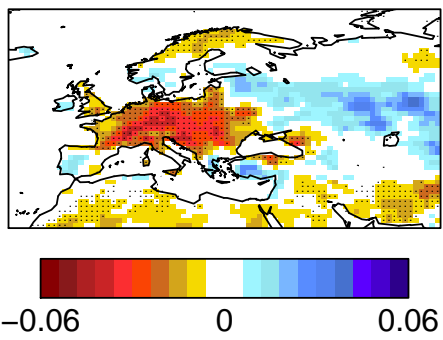

b) t2m: CLIM

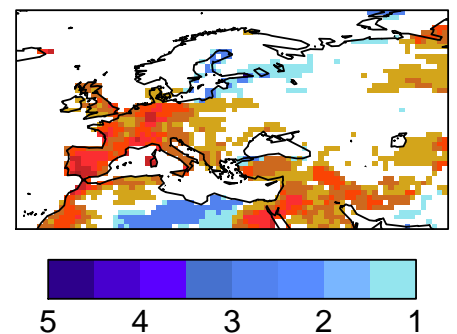

e) precip: CLIM

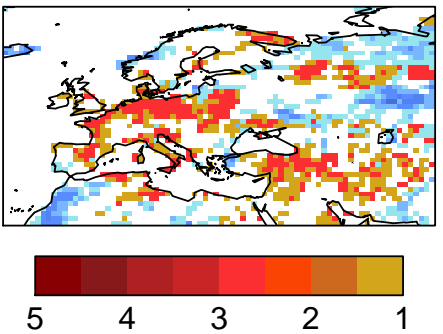

h) z500: CLIM

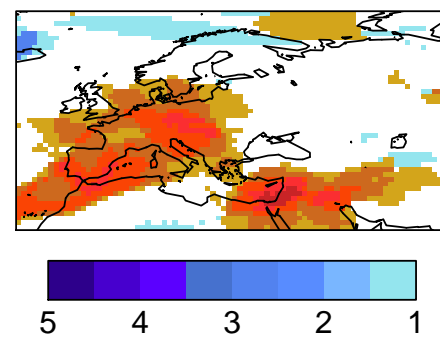

k) SLP: CLIM

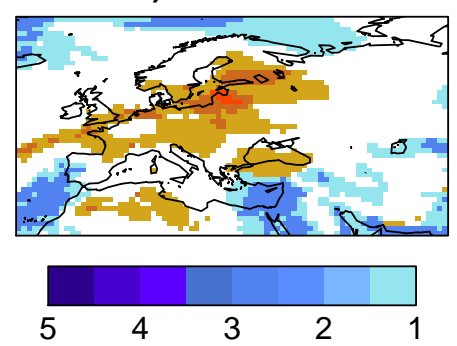

n) soil moisture: CLIM

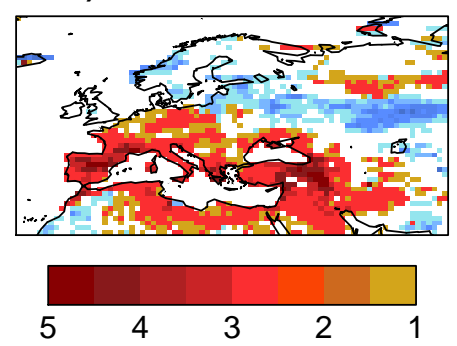

c) t2m: INIT

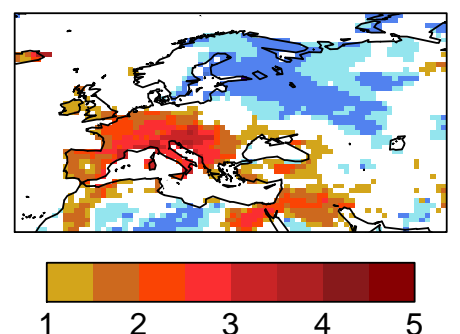

f) precip: INIT

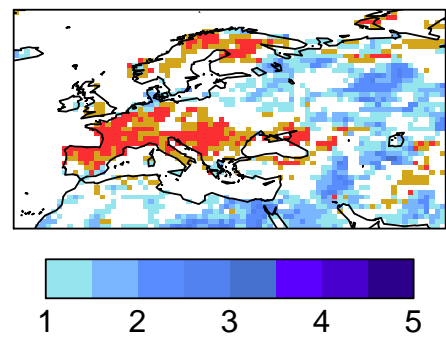

i) z500: INIT

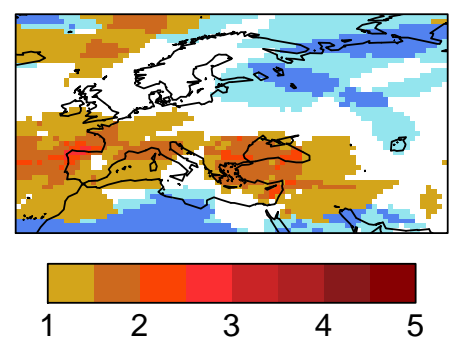

I) SLP: INIT

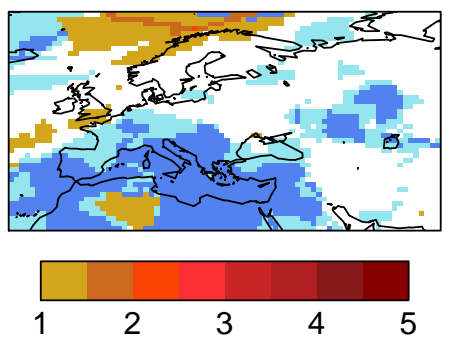

o) soil moisture: INIT

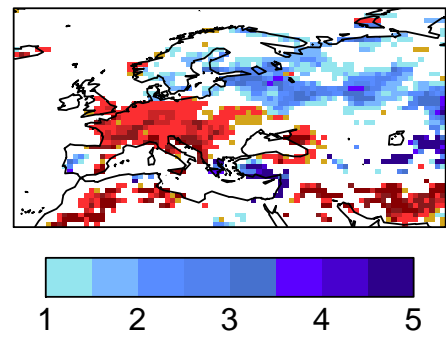

Fig. 7: a Observed anomalies of $\mathrm{t} 2 \mathrm{~m}$ for 2003 JJA (one-month lead time) mean (K). The dots indicate the area where the anomaly is in the upper quintile (estimated over 1981-2010). b Odds in CLIM for $\mathrm{t} 2 \mathrm{~m}$. The odds are the ratio between the probability for the anomalies to be in the upper quintile, the interquintile range or the lower quintile and with the climatological probability of these three categories $(20 \%, 60 \%$ and $20 \%$, respectively). Each point is attributed to the category corresponding to the highest odds ratio. If the point is attributed to the interquintile range or if there is no category assigned (the categories with two highest odds ratio have an equal value) the point is drawn in white. If the point is attributed to the lower/upper quintile category, the corresponding odds ratio is plotted with the left/right color scale. c Same as $\mathbf{b}$, but for INIT. d Observed anomalies of precipitation for 2003 JJA mean (mm/day). The dots indicate the area where the anomaly is in the lower quintile for the 1981-2010 period. e same as $\mathbf{b}$, but for precipitation. f Same as $\mathbf{c}$, but for precipitation. $\mathbf{g}, \mathbf{h}, \mathbf{i}$ same as $\mathbf{a}, \mathbf{b}, \mathbf{c}$, but for geopotential height at $500 \mathrm{hPa}(\mathrm{m})$. j, k, $\mathbf{l}$ same as $\mathbf{a}, \mathbf{b}, \mathbf{c}$ but for monthly mean of 6 hourly SLP (hPa). $\mathbf{m}, \mathbf{n}, \mathbf{o}$ same as $\mathbf{d}, \mathbf{e}, \mathbf{f}$ but for the vertically integrated volume fraction of water in soil $\left(\mathrm{m}^{3} / \mathrm{m}^{3}\right)$. 
a) t2m: ERAint

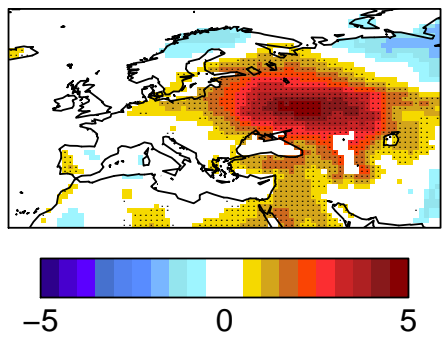

d) precip: ERAint

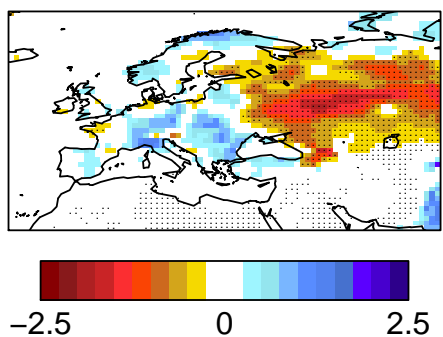

g) z500: ERAint
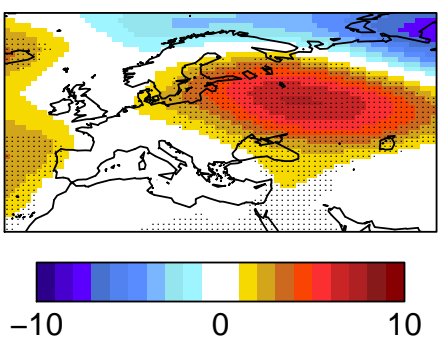

j) SLP: ERAint
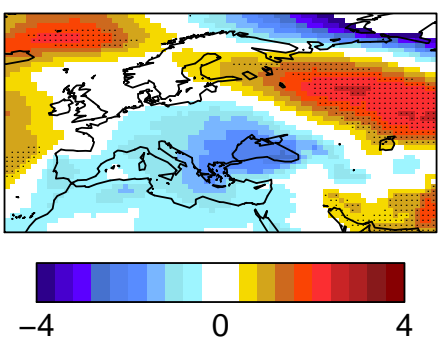

m) soil moisture: ERAland
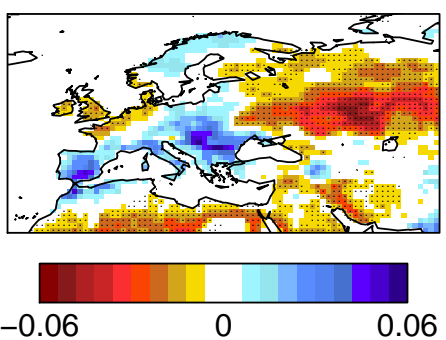

b) t2m: CLIM

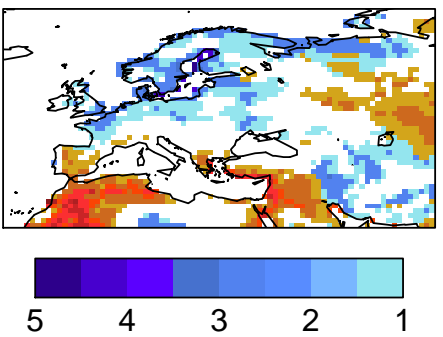

e) precip: CLIM

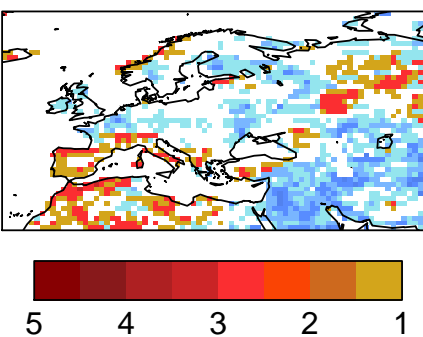

h) z500: CLIM

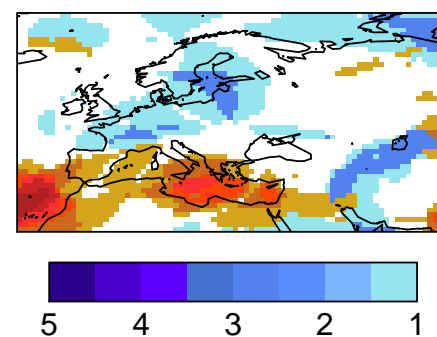

k) SLP: CLIM
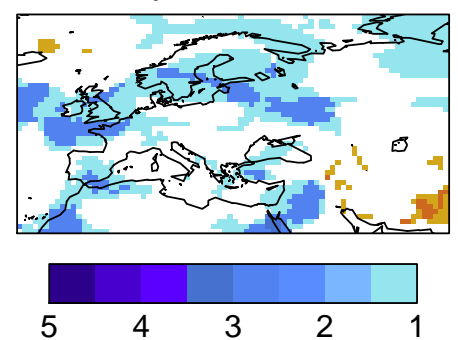

n) soil moisture: CLIM

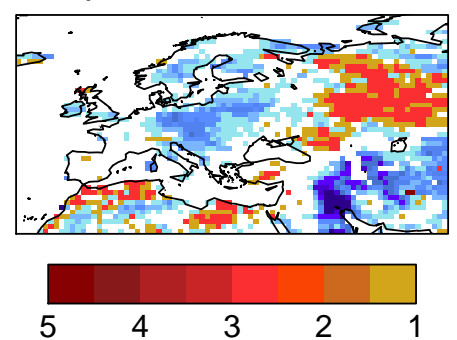

c) t2m: INIT

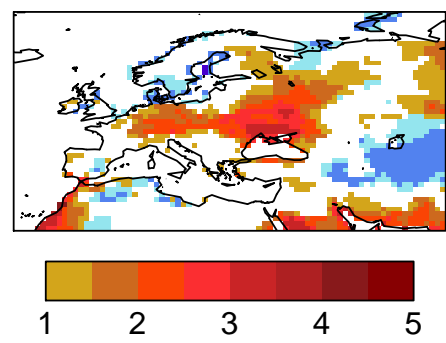

f) precip: INIT

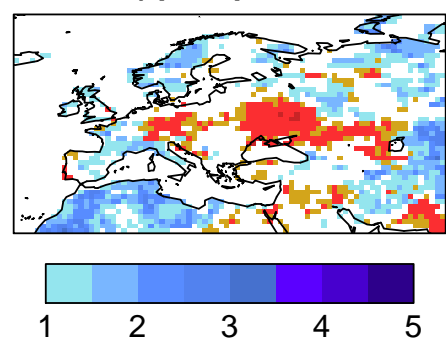

i) Z500: INIT
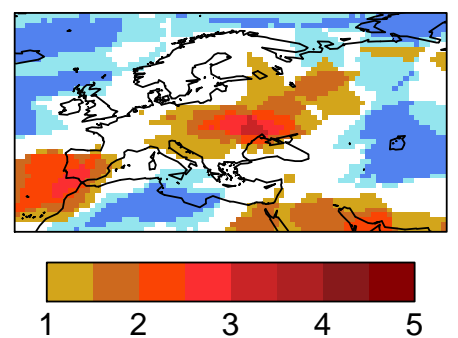

I) SLP: INIT
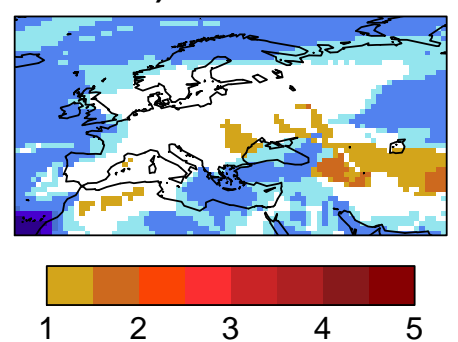

o) soil moisture: INIT

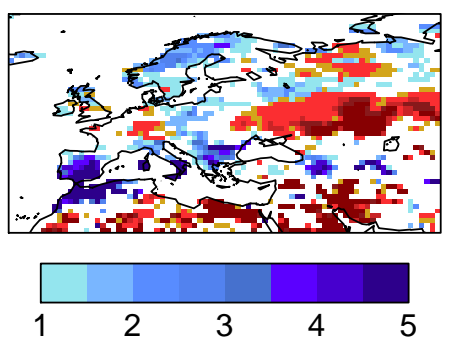

Fig. 8: Same as Fig. 7, but for JJA (one-month lead time) 2010. 
a) soil moisture anomalies 1st of May 2003

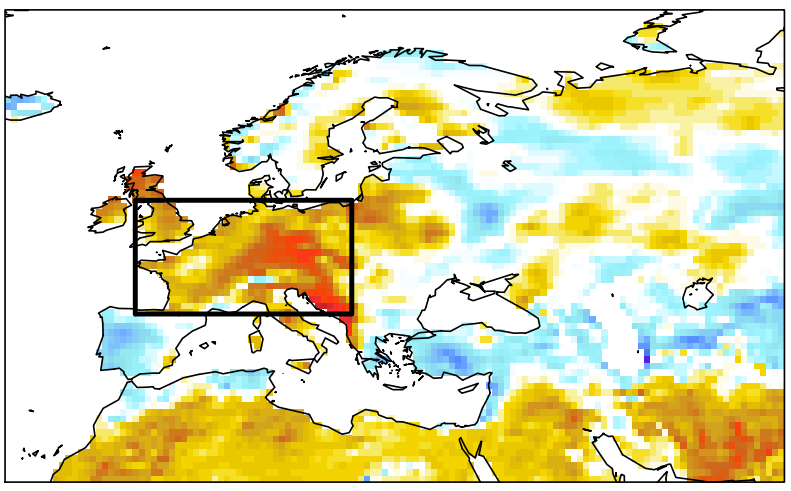

d) soil moisture anomalies 1st of May 2010
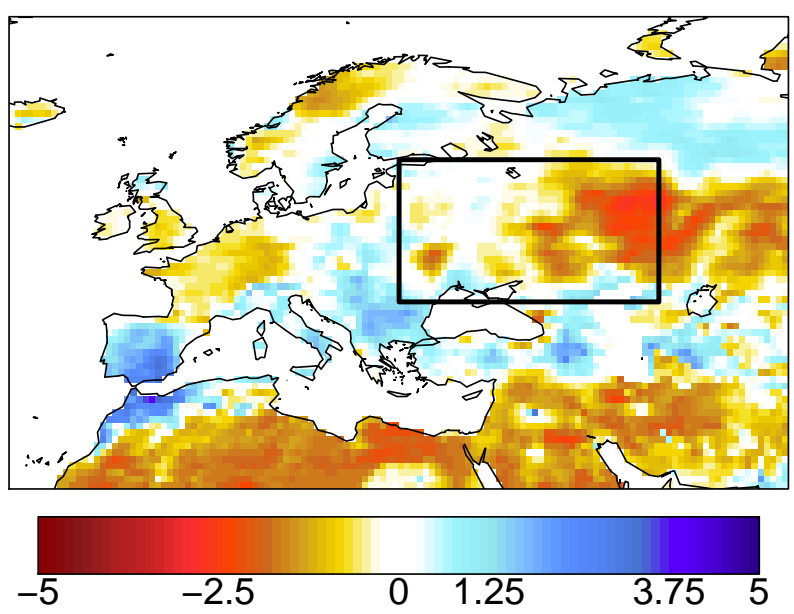

b) daily anomalies in 2003

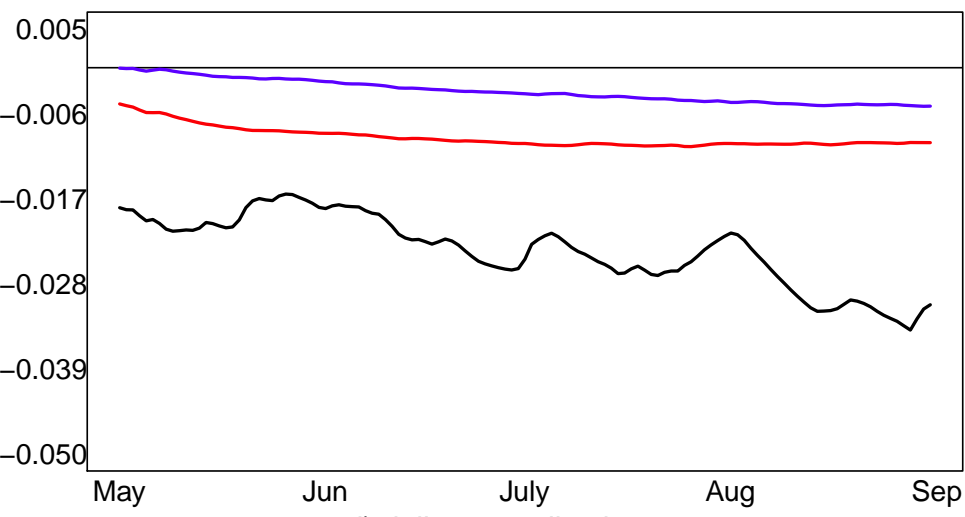

d) daily anomalies in 2010

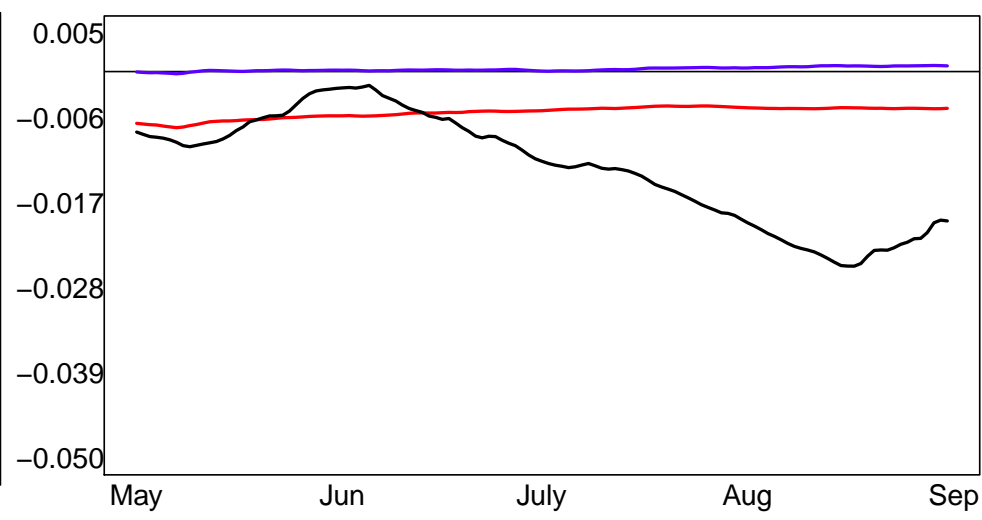

Fig. 9: a Standardized anomalies with respect to the daily climatology computed over 19812010 of ERA-Land for May 1st 2003. b Evolution of the daily anomalies of summer 2003 averaged in the black box of a (5W20E-43N55N) in black for ERA-Land, in blue for the ensemble mean of CLIM and in red for the ensemble mean of INIT. $\mathbf{c}$ Same as a but for May 1st 2010. d Same as b but for the box drawn on c (25E55E-45N60N) during summer 2010. For all the panel the unit is $\mathrm{m}^{3} / \mathrm{m}^{3}$. 


\section{Click here to access/download \\ Electronic Supplementary Material sup.pdf}

